\title{
Foundations for a multiscale collaborative global Earth model
}

\author{
Michael Afanasiev, ${ }^{1}$ Daniel Peter, ${ }^{1,2,{ }^{*}}$ Korbinian Sager, ${ }^{1}$ Saulè Simutė, ${ }^{1}$ Laura Ermert, ${ }^{1}$ \\ Lion Krischer $^{3}$ and Andreas Fichtner ${ }^{1}$ \\ ${ }^{1}$ Department of Earth Sciences, Institute of Geophysics, ETH Zurich, Zurich, Switzerland. E-mail: michael.afanasiev@erdw.ethz.ch \\ ${ }^{2}$ Institute of Computational Sciences, Advanced Computing Laboratory, Universita della Svizzera Italiana, Lugano, Switzerland \\ ${ }^{3}$ Department of Earth and Environmental Sciences, Institute of Geophysics, Ludwig Maximilian University, Munich, Germany
}

\begin{abstract}
SUMMAR Y
We present a computational framework for the assimilation of local to global seismic data into a consistent model describing Earth structure on all seismically accessible scales. This Collaborative Seismic Earth Model (CSEM) is designed to meet the following requirements: (i) Flexible geometric parametrization, capable of capturing topography and bathymetry, as well as all aspects of potentially resolvable structure, including small-scale heterogeneities and deformations of internal discontinuities. (ii) Independence of any particular wave equation solver, in order to enable the combination of inversion techniques suitable for different types of seismic data. (iii) Physical parametrization that allows for full anisotropy and for variations in attenuation and density. While not all of these parameters are always resolvable, the assimilation of data that constrain any parameter subset should be possible. (iv) Ability to accommodate successive refinements through the incorporation of updates on any scale as new data or inversion techniques become available. (v) Enable collaborative Earth model construction. The structure of the initial CSEM is represented on a variable-resolution tetrahedral mesh. It is assembled from a long-wavelength 3-D global model into which several regional-scale tomographies are embedded. We illustrate the CSEM workflow of successive updating with two examples from Japan and the Western Mediterranean, where we constrain smaller scale structure using full-waveform inversion. Furthermore, we demonstrate the ability of the CSEM to act as a vehicle for the combination of different tomographic techniques with a joint fullwaveform and traveltime ray tomography of Europe. This combination broadens the exploitable frequency range of the individual techniques, thereby improving resolution. We perform two iterations of a whole-Earth full-waveform inversion using a long-period reference data set from 225 globally recorded earthquakes. At this early stage of the CSEM development, the broad global updates mostly act to remove artefacts from the assembly of the initial CSEM. During the future evolution of the CSEM, the reference data set will be used to account for the influence of small-scale refinements on large-scale global structure. The CSEM as a computational framework is intended to help bridging the gap between local, regional and global tomography, and to contribute to the development of a global multiscale Earth model. While the current construction serves as a first proof of concept, future refinements and additions will require community involvement, which is welcome at this stage already.
\end{abstract}

Key words: Inverse theory; Seismic tomography; Computational seismology; Wave propagation.

\footnotetext{
*Now at: Division of Physical Sciences and Engineering, King Abdullah University of Science and Technology (KAUST), Thuwal 23955-6900, Kingdom of Saudi Arabia.
}

\section{INTRODUCTION}

Recent advances in computational power, along with the everincreasing availability of seismic data, have bred an unprecedented number of seismic Earth models. Over the past $40 \mathrm{yr}$, seismic tomography has produced Earth models on the order of metres, kilometres, hundreds to thousands of kilometres, as well as models of the entire globe. While dramatic progress has been made since its 
first applications (e.g. Aki \& Lee 1976; Aki et al. 1976; Dziewoński et al. 1977), this proliferation of models has brought to light two key issues: First, tomographic models for the same geographic region tend to differ over length scales that individual authors expect to be resolved. This is the case for the most reliably imaged isotropic velocities (e.g. Becker \& Boschi 2002; Fichtner et al. 2012; Schaeffer \& Lebedev 2013), and even more so for less well constrained properties such as attenuation (e.g. Dalton et al. 2008). Second, Earth models are mostly parametrized at similar spatial scale, despite the fact that tomographic resolution within a model may vary by orders of magnitude. Exceptions are mostly limited to a few ray tomography studies where global and regional data were integrated (e.g. Bijwaard et al. 1998; Wang et al. 1998; Boschi et al. 2004; Schäfer et al. 2011; Auer et al. 2014).

These issues complicate the interpretation and use of tomographic Earth models. While the difficulties arising from the first are immediately clear, the difficulties from the second become apparent when considering the impact of potentially unresolved small-scale structure on images of large-scale properties. Both problems stem from the lack of intermodel communication, discrepant forward and inverse methods and incomplete data sets. Each model inherits the unique imprint of its data set and resolved scale length, with communication between data sets and scales occurring only loosely via common starting models. Currently missing is a framework which seeks to consolidate the space of Earth models; which attempts to steer seismic tomography toward global convergence across data sets and scales. Providing such a framework is the declared goal of the effort presented here.

\subsection{Differences between Earth models}

From the standpoint of inverse theory, the lack of similarity between Earth models is not surprising. Tomographic problems are often simultaneously over- and underdetermined, with determinedness varying geographically as a function of data coverage. This mixed-determinedness requires the introduction of regularization to stabilize inversions, a process which, while guided by physical intuition, ultimately forces some degree of subjectivity. Additionally, the character of the determinedness itself is dependent upon the specifics of the geometric model parametrization, which varies significantly between models and may be in terms of spherical harmonics (e.g. Dziewoński et al. 1977; Ritsema et al. 2004; Dalton et al. 2008; Ritsema et al. 2011), spherical splines (e.g. Wang \& Dahlen 1995; Nettles \& Dziewoński 2008; Yoshizawa \& Ekström 2010), constant-velocity blocks (e.g. Aki \& Lee 1976; Aki et al. 1976; Spakman et al. 1993; Fichtner et al. 2009a), the mesh of a spectral-element solver (e.g. Tape et al. 2010; Zhu et al. 2015), or wavelets (e.g. Charléty et al. 2013). As geometric parametrization is often intimately tied to the particular forward and inverse techniques used, the choice of these techniques are imprinted on the final models as well.

A perusal of the data sets used in tomographic inversion brings to light an additional, more fundamental, reason why models differ: The data used for the construction of a particular model are usually different from the data used for another. Frequently used data include surface wave dispersion (e.g. Trampert \& Woodhouse 1995, 2003; Shapiro et al. 2005; Ekström 2011), body wave traveltimes (e.g. Aki \& Lee 1976; Spakman et al. 1993; Kennett et al. 1998; Li et al. 2008), normal mode spectra (e.g. Giardini et al. 1987; Resovsky \& Ritzwoller 1999; Ishii \& Tromp 2001, 2004), or combinations of these (e.g. Nolet 1978; Ritsema et al. 2004; Mégnin \& Romanowicz 2000; Lebedev \& van der Hilst 2008; Chang et al. 2010; Ritsema et al. 2011). Data used in a particu- lar model may simply be insensitive to parameters which are well sampled by data used in another, thereby contributing to differences between models.

Within the seismic frequency band, the Earth is a viscoelastic and fully anisotropic body. Not all of the physical parameters describing its rheology are equally well resolved by seismic data. For instance, density and most parameters describing anisotropy lie close to the null space of most data sets. Therefore, the number of physical parameters is generally reduced, meaning that all current models represent a projection of the complete set of physical parameters - anisotropic seismic velocities, their respective attenuation and density - onto a subspace. The details of this projection depend on the subjective selection of parameters, and on the sensitivity of the chosen seismic data to them. Clearly, the choice of physical model parameters adds to the differences between tomographic models.

While the need and subjectiveness of regularization cannot be avoided, the impact of geometric parametrization, different data sets and physical parametrization may be reduced. Achieving this goal is a key motivation of this work.

\subsection{Scale dependence}

Early seismic tomography was based on the ray approximation (e.g. Aki \& Lee 1976; Aki et al. 1976; Dziewoński et al. 1977). Advances in mathematical seismology led to the development of normal-mode inversions (e.g. Woodhouse \& Dziewoński 1984; Giardini et al. 1987; Deuss \& Woodhouse 2001), finite-frequency methods (e.g. Yomogida 1992; Dahlen et al. 2000; Friederich 2003; Yoshizawa \& Kennett 2005) and tomographic techniques based on the fully numerical solution of the wave equation in complex heterogeneous media (e.g. Igel et al. 1996; Pratt 1999; Chen et al. 2007; Fichtner et al. 2009a; Tape et al. 2010; Kamei et al. 2012; Smithyman \& Clowes 2012). The successive incorporation of more accurate wave propagation physics reduces artefacts that arise from simplifications of the forward problem, and thereby contribute to the improvement of tomographic resolution.

Regardless of the inversion technique, tomographic models are homogenized, or effective, versions of the more complex Earth (Capdeville et al. 2010a; Capdeville \& Cance 2015; Capdeville et al. 2015). The way in which models are effective depends on the frequency content of the data (physical homogenization) and on the inverse method-specific regularization that compensates for a lack of coverage (technical homogenization). It follows that there is no unique large-scale Earth, as every model represents its structure as filtered subjectively through its associated data set and frequency band. The theory of physical homogenization (e.g. Backus 1962; Levshin \& Ratnikova 1984; Schoenberg \& Muir 1989; Babuška \& Cara 1991; Capdeville et al. 2010b) reveals a dark side of tomographic inversion: scale dependence, that is the mapping of unresolved small-scale structure into large-scale properties. Prominent facets of scale dependence are the pollution of imaged anisotropy by unknown details of crustal structure (Ferreira et al. 2010) and the perfect equivalence of radial anisotropy and fine layering in Earth models with finite resolution (Fichtner et al. 2013a). The consequence for the interpretation of seismic Earth models is that any inverted anisotropy may be nothing more than an artefact of the inverted wavelengths, and may indeed disappear as resolution is increased.

Reducing scale dependence through the increase of resolution requires improvements in spatial coverage and the inversion of seismic data at higher frequencies. Unfortunately, the computational cost of numerically solving the wave equation scales with frequency and 
the generation of accurate synthetic short-period seismograms on the global scale quickly becomes unfeasible. Even if computational power were not a concern, the nonlinearity of the inverse problem becomes more severe as the number of propagated wavelengths increases. These difficulties have traditionally led to the production of what may be classified as nearly monoscale models that describe Earth structure either on the global or regional scale - ignoring that the scales are coupled.

\subsubsection{Global models}

Global tomographic Earth models (e.g. Ritsema et al. 2011; Lekić \& Romanowicz 2011; Debayle \& Ricard 2012; Schaeffer \& Lebedev 2013; Auer et al. 2014) generally use smooth 3-D or 1-D radially symmetric Earth models (e.g. Dziewoński \& Anderson 1981; Kennett \& Engdahl 1991; Kennett et al. 1995) as starting point. The result is a tree-like structure, with many global models branching from a relatively small number of starting models. Taken together, they represent an ensemble of possible global structure over regularization philosophies, data types, forward solvers and inverse techniques.

While seismic data or previous tomographies on smaller scales would help to reduce model dissimilarity and scale dependence, they are usually ignored in these global studies. The reasons are mostly of computational nature: Frequently used forward modelling approaches such as ray theory and the Born approximation lose their validity in the presence of strong small-scale heterogeneities (e.g. Črvený 2005; Panning et al. 2009; Parisi et al. 2015). Forward problem solvers based on finite differences (e.g. Moczo et al. 2002; Bohlen 2002; Moczo et al. 2014) or finite elements (e.g. Seriani \& Priolo 1994; Faccioli et al. 1996; Komatitsch \& Vilotte 1998 ) would require a very small grid spacing to capture known small-scale structure, thereby exceeding commonly available computational resources. As a result the scale length of resolvable structure in 3-D global models mostly hovers around $1000 \mathrm{~km}$.

\subsubsection{Regional models}

To exploit information contained in short-period waveforms, the simulated model volume may be decreased. This results in the computational effort being concentrated on a smaller geographical region where the cost of modelling short-period waves becomes reasonable. To accelerate convergence, regional tomography may use a pre-existing chunk of a global model as a starting point (e.g. Fichtner et al. 2009a; Zhu et al. 2015). The regional inversion introduces small-scale perturbations, which reflect the new information contained in the short-period data, overtop the smooth global background.

It is at this point that the analysis of regional models usually stops. The information gain on the small scales is normally not used to improve the global model from which it was derived. The result is the aforementioned scale gap, where global scale or regional scale models coexist with little interaction.

\subsection{Objectives: towards a multiscale and collaborative seismic Earth model}

The main objective of the work presented here is the development of a computational framework for the consistent assimilation of seismic data on all spatial scales and in a broad frequency range. This is intended to enable the construction of a consistent multiscale
Collaborative Seismic Earth Model (CSEM). The CSEM is built around the following five axioms.

(i) Flexible geometric parametrization: The geometric parametrization of the CSEM should be flexible enough to capture all aspects of Earth structure that are potentially resolvable or that may affect the seismic wavefield. These aspects include topography of the surface and internal discontinuities, as well as small-scale heterogeneities.

(ii) Forward solver independence: The geometric parametrization of the CSEM should not be tailored towards particular forward problem solvers that are popular today or may become popular in the future. Instead, suitably simplified Earth models should be extracted from the CSEM to operate solvers that handle a certain degree of complexity in seismic wave propagation physics.

(iii) Physical parametrization: The physical parametrization of the CSEM should allow for the presence of full anisotropy, as well as for 3-D variations in density and attenuation. While not all of these parameters are always resolvable, this strategy is intended to allow for the assimilation of data that do constrain them.

(iv) Updating: The CSEM as a computational framework should be able to include updates on any scale as new seismic data or inversion techniques become available.

(v) Collaboration: The complexity of inverting a given seismic data set - in terms of both computational time and physical human effort-grows rapidly with the size of the data set. In order to ensure that the costs to any given research group remain tractable, the CSEM should promote the parallelization of inversions over research groups.

In Section 2, we describe the general philosophy and construction of the CSEM. This includes the geometric and physical parametrization, the extraction of submodels for regional refinement, the reincorporation of these regional updates into the global multiscale CSEM, as well as the construction of the initial CSEM through the combination of a global 3-D model with various regional fullwaveform tomographies. The workflow for the successive updating of the CSEM is presented in Section 3. In this context, we provide examples of regional full-waveform inversion updates for Japan and the Western Mediterranean. We also demonstrate that the CSEM provides a framework for the combination of different tomographic techniques, using the example of a combined full-waveform inversion and traveltime ray tomography. Two global full-waveform iterations are subsequently shown to remove long-wavelength artefacts from the assembly of the initial CSEM, and to improve Earth structure in regions that were previously poorly covered. Finally, we discuss the outlook for the model, and comment on some areas ripe for future research.

\section{MULTISCALE MODEL CONSTRUCTION}

In the following paragraphs, we describe the implementation of the CSEM in terms of its physical and geometrical parametrization, computational implementation and initial Earth structure. More technical details regarding the storage and model-solver interfaces can be found in Appendices.

\subsection{Physical parametrization}

Earth structure in the CSEM is described in terms of 3-D variations in the 21 elastic parameters, shear and compressional attenuation 
Table 1. A list of the different radial regions, along with their corresponding radial discretization.

\begin{tabular}{cc}
\hline Region $(\mathrm{km})$ & Radial discretization $(\mathrm{km})$ \\
\hline $6351-6371$ & 1 \\
$6271-6351$ & 2 \\
$3480-6271$ & 5 \\
$1221-3480$ & 50 \\
$0-1221$ & 50 \\
\hline
\end{tabular}

and density. Not all of these parameters can be resolved by a specific data set. However, this overparametrization is intended to offer maximum flexibility, without restricting the model to a particular system of symmetry that may not be compatible with seismic data that could be incorporated in future updates.

The initial construction of the model, to be described in Section 2.4, contains contributions from models that considered transversely isotropic media, and as a result many of the stored parameters are identically zero. To work with specific forward and inverse problem solvers that require a less general rheology, the fully anisotropic CSEM may be projected onto a lower dimensional subspace, or transformed into a more classical parametrization.

\subsection{Geometric parametrization}

At the lowest level, the CSEM is parametrized by a tetrahedral finite-element mesh. At each node point in the mesh, the 21 elastic parameters needed to completely characterize an elastic medium are stored. In addition, density, the quality factor $Q$ (shear and bulk) and local element size are stored as well. In order to combat the problems associated with large files, the mesh is split into 8 chunks, each spanning $90^{\circ}$ in latitude and longitude. Additionally, each chunk is split radially into 45 regions. Between each radial region, the region-specific discretization in radius is allowed to vary. A list of these regions, and their corresponding default discretizations, is given in Table 1. The default discretization in the latitude-longitude directions is $100 \mathrm{~km}$. Regions of the mesh respecting these parameters are referred to as the 'background mesh'. All mesh generation is handled by Trelis Blacker \& Stephenson (1991), a proprietary mesh generation software developed by Sandia National Labs and csimsoft $^{\mathrm{TM}}$.

High-resolution subregions are accommodated within the CSEM by locally refining the background mesh in the latitude-longitude direction. The size of the refined mesh is ideally set to one half of the estimated resolution lengths of the subregions, in an attempt to accurately sample all resolved wavenumbers. If the size of the refined latitude-longitude mesh drops below the radial discretization of the region, the mesh is automatically refined in the radial direction as well. A rendering of the initial CSEM mesh is shown in Fig. 1. In contrast to models that seek to constrain Earth structure with as few parameters as possible, the CSEM is deliberately overparametrized in order to capture all potentially resolved features. Clearly, not all representable length scales are resolvable everywhere in the model. However, numerous methods to quantify the extent to which they are, already exist for nearly linear inverse problems (Backus \& Gilbert 1968, 1970; Deal \& Nolet 1996; Yanovskaya 1997; Nolet et al. 1999; Boschi 2003), and are being developed for computationally more intense full-waveform inversion techniques (Fichtner \& Trampert 2011; Fichtner \& van Leeuwen 2015).

Tetrahedra were chosen due to the ease with which they can be used to mesh complex geometries. As high-resolution subregions are added to the model, this benefit becomes apparent. As the number of subregions grows, each one with a unique shape, model geometry becomes increasingly complex. The meshing of the resulting geometry would become increasingly difficult with hexahedra, to the point of impossibility. Generating the mesh with tetrahedra allows this to be accomplished with ease, and as a result all mesh operations are handled automatically with Python-Trelis wrappers. To avoid confusion, we note that the tetrahedral mesh that comprises the CSEM is not (currently) meant to support wavefield simulations, but instead acts as a convenient storage framework. However, we do not rule out this usage case for the future. Indeed, as described in Appendix A, the model is stored in a form which is designed for use with finite-element type methods.

\subsection{Communicating with the mesh}

With the parametrization defined, we designed an application interface to communicate with the mesh (csemLib). The practical purpose of csemLib is to facilitate the extraction and interpolation of subregions, and to export these subregions in solver-specific parameter files. While allowing for great flexibility, the philosophy of oversampling described in Section 2.2 necessitated that the computational efficiency of csemLib be prioritized, as the number of model parameters will grow rapidly as high-resolution subregions are added.

\subsubsection{Interpolation from an arbitrary (regional, high resolution) model volume to the CSEM mesh}

The interpolation of new models generated externally from the CSEM onto the CSEM mesh is not a simple matter of overwriting a current parameter in the mesh with an updated parameter. If we proceeded in this manner, we may destroy stored information. Instead, we add updated perturbations from the external model volume onto the CSEM mesh. To see the benefits of this technique, consider a continental-scale tomography of an external model volume that coincides with several high-resolution subregions in the CSEM mesh. If the entire model volume was exchanged for the updated parameters from the continental-scale inversion, fine-scale structure in the subregions would be destroyed. On the contrary, adding only model updates allows us to retain all the fine-scale information, modifying the long-wavelength background if necessary.

The interpolation stage loops over all node points in the CSEM mesh which lie within the bounds of the external model volume. A nearest-neighbour search between a point in the model volume and a point in the CSEM mesh is implemented via a KD-tree (Bentley 1975). Once the closest point is found, the difference between the parameter in the model volume at the final iteration, and the parameter at the initial iteration, is added to the existing parameter in the CSEM mesh. If the model is not fully anisotropic, the parameters provided (e.g. $v_{\mathrm{sh}}, v_{\mathrm{sv}}, v_{\mathrm{p}}$, etc.) are decomposed into their tensor components.

Since the CSEM mesh is always oversampled with respect to the highest wavenumber heterogeneities in the external model volume, interpolation errors stemming from the nearest neighbour approach are within uncertainty.

\subsubsection{Extraction of subregions from the CSEM for regional refinement}

The extraction of a model subvolume from the CSEM mesh for use with an external solver is more involved than the interpolation stage. This is because, contrary to the interpolation stage, the original CSEM mesh may undersample the resolution of the external 


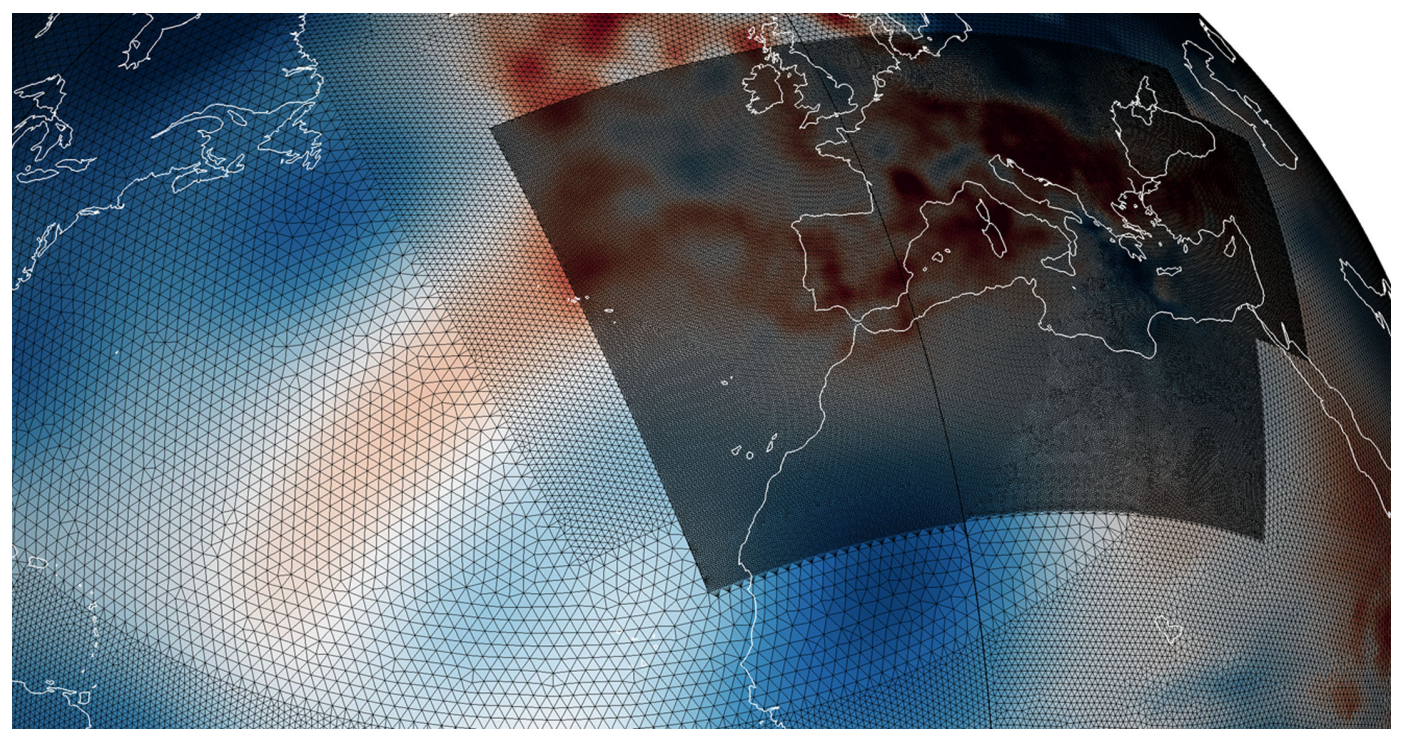

Figure 1. Illustration of the skeletal mesh underlying the CSEM. The coarsest submesh visible has approximately $100 \mathrm{~km}$ gridpoint spacing, maintaining the radial discretization given in Table 1. With a spacing of $\sim 15 \mathrm{~km}$, the discretization is finest within Anatolia. The discretizations here are meant to oversample the smallest heterogeneities present, and should not be taken as a resolution estimate. The interpolated SH velocities, shown at $100 \mathrm{~km}$ depth, range from red (slow) to blue (fast), and are included here only to aid in visualization. Their features will be described in detail in Sections 3.1.2 and 4.1.

parametrization. In fact, high-resolution regional tomographies are meant to use an extraction from the CSEM as a starting model. Since the CSEM is always oversampled in relation to the models it currently contains, a simple linear interpolation over tetrahedra is sufficient to accurately preserve heterogeneity during the extraction.

The implementation of the extraction routine is non-trivial for computational reasons. For example, the mesh required for a global wave propagation simulation may require parameters defined at more than $1 \times 10^{9}$ points and the current CSEM itself is comprised of approximately $1 \times 10^{9}$ elements. With problems of this scale, it is imperative that an efficient method be used to determine which tetrahedron contains a given 3-D point - an exhaustive search of all tetrahedra is much too costly.

We begin our approach to this problem by slightly modifying the methods described in Section 2.3.1. Now, instead of using a KD-tree to find the closest node to a given point $\mathbf{p}$, we use the tree to build a set $\mathbf{C}$ of all nodes that lie within a distance $d$ of $\mathbf{p}$. The barycentric coordinate transform is then applied to each tetrahedron which has a node in $\mathbf{C}$ as a vertex. This transformation has the form

$$
\begin{aligned}
\left(\begin{array}{l}
\lambda_{1} \\
\lambda_{2} \\
\lambda_{3}
\end{array}\right) & =\mathbf{T}^{-1}\left(\mathbf{p}-\mathbf{r}_{4}\right) \\
\lambda_{4} & =1-\lambda_{1}-\lambda_{2}-\lambda_{3}
\end{aligned}
$$

where $r_{i}=\left(x_{i}, y_{i}, z_{i}\right)$ are the spatial coordinates of the four vertices which define the tetrahedron and $\mathbf{T}$ is the matrix

$$
\left(\begin{array}{ccc}
x_{1}-x_{4} & x_{2}-x_{4} & x_{3}-x_{4} \\
y_{1}-y_{4} & y_{2}-y_{4} & y_{3}-y_{4} \\
z_{1}-z_{4} & z_{2}-z_{4} & z_{3}-z_{4}
\end{array}\right) \text {. }
$$

The values $\lambda_{1}, \lambda_{2}, \lambda_{3}$ and $\lambda_{4}$, known as the barycentric coordinates, represent $\mathbf{p}$ in terms of the vertices of a given tetrahedron. The point $\mathbf{p}$ is located within the tetrahedron if

$0 \leq \lambda_{i} \leq 1 \forall i$ in $1,2,3,4$.

The condition in eq. (3) is tested for all tetrahedra attached to nodes in $\mathbf{C}$, until the tetrahedron containing $\mathbf{p}$ is found. Once this occurs, we can find the interpolated parameter $\alpha_{\mathbf{p}}$ at $\mathbf{p}$ by a linear combination of the parameters defined at the node points $\left(\alpha_{\mathbf{r}_{i}}\right)$.

$\alpha_{p}=\lambda_{1} \alpha_{r_{1}}+\lambda_{2} \alpha_{r_{2}}+\lambda_{3} \alpha_{r_{3}}+\lambda_{4} \alpha_{r_{4}}$.

If the tetrahedron containing $\mathbf{p}$ is not found, $d$ is incrementally increased until the search is successful. As well, if a certain value of $d$ has historically produced successful sets $\mathbf{C}, d$ is slowly decreased until a set is found which does contain $\mathbf{p}$. This strategy keeps the search algorithm quick and efficient, and is invaluable in regions where the mesh size may vary widely.

Due to the discrete nature of the CSEM mesh chunks, some requested coordinates $\mathbf{p}$ lie just outside of the mesh boundaries, and as a result will fail the test in eq. (3) for all tetrahedra. In this case, a set of the outward facing facets belonging to the bounding tetrahedra is built. $\mathbf{p}$ is then projected in the direction of the nearest facet, so at least the strict equality in eq. (3) is satisfied. This ensures that discontinuities in the mesh are properly handled and also eases the implementation of physical discontinuities within the Earth.

\subsection{Construction of the initial CSEM}

Before we proceed in Section 3 with the description of the workflow used to successively update the CSEM with new data, we describe the construction of the initial CSEM, which is a compilation of global and regional 3-D Earth models.

As 1-D starting point, we used the Preliminary Reference Earth Model (PREM; Dziewoński \& Anderson 1981) with the following modifications. The original discontinuity at $220 \mathrm{~km}$ depth was replaced by a linear gradient. We ignore the poorly constrained $P$-wave anisotropy, and use linear depth-dependent scaling between $v_{\mathrm{sv}}$ and $v_{\mathrm{sh}}$ in the upper $220 \mathrm{~km}$. A figure of the resulting 1-D background can be seen in Fig. 2.

Added to this background are the 3-D $S$-velocity perturbations from S20RTS (Ritsema et al. 1999). These perturbations are mapped to $P$-velocity perturbations using the $P$-to- $S$ scaling proposed by Ritsema \& van Heijst (2002). The initial crustal model is the one derived by Meier et al. (2007a,b), which includes estimations of both 


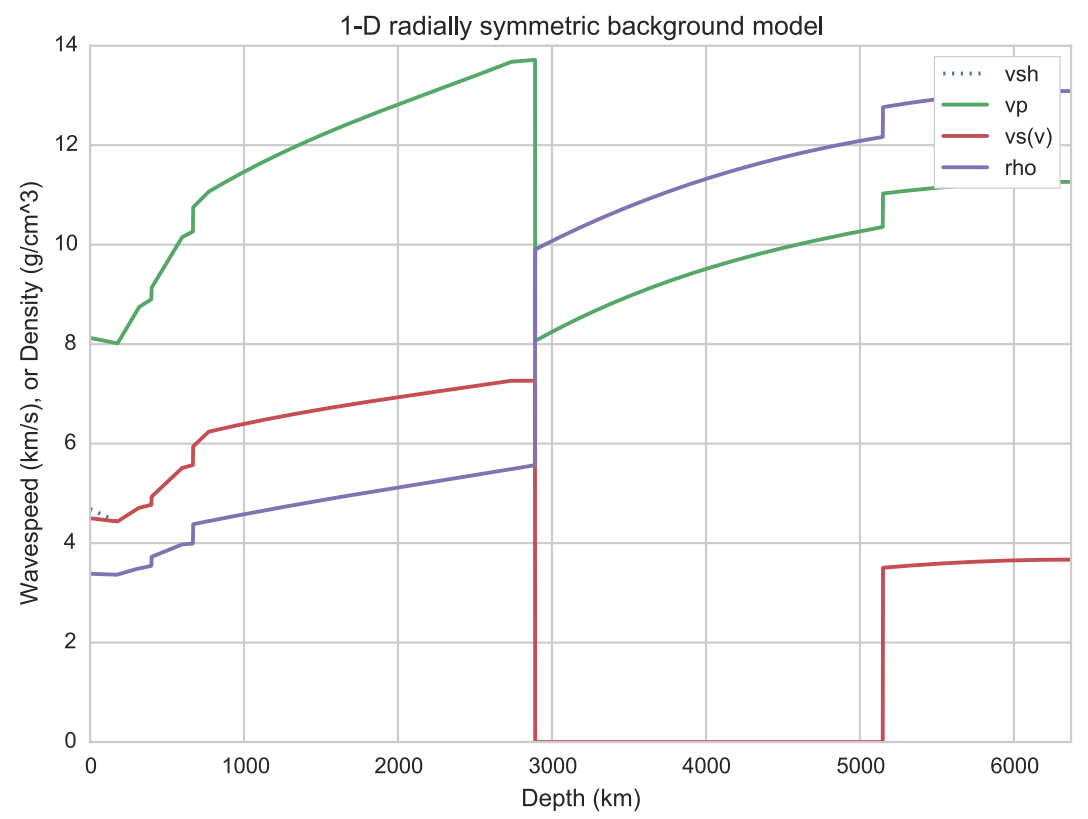

Figure 2. An illustration of the 1-D radially symmetric background model used in the CSEM. The model is derived from PREM (Dziewoński \& Anderson 1981). Differences include the replacement of the discontinuity at $220 \mathrm{~km}$ depth by a linear gradient, the neglect of $P$-wave anisotropy and the depth-dependent scaling between $v_{\mathrm{sh}}$ and $v_{\mathrm{sv}}$ above $220 \mathrm{~km}$ that takes the form $v_{\mathrm{sh}}=v_{\mathrm{sv}}+0.0011 *$ (radius -220 ) $\mathrm{km} \mathrm{s}^{-1}$. Near the surface, the mantle velocities and parameters are stretched up to the Moho depth estimate given by Meier et al. (2007b), above which they are replaced by crustal values.

$S$-wave velocity and crustal thickness. These parameters are interpolated onto the CSEM mesh via a bilinear interpolation. Crustal values are only used for node points which are above the estimated Moho depth, below this depth the mantle values from the 1-D background and S20RTS are stretched upwards if necessary. Within the crust, mappings from $S$ velocity to $P$ velocity and density are those given by Meier et al. (2007a).

Higher resolution submodels were incorporated into the initial CSEM for the following regions: Australia (Fichtner et al. 2009a, 2010), Japan (Diaz-Steptoe 2013), the South Atlantic (Colli et al. 2013) and Europe with an embedded regional model of Anatolia (Fichtner et al. 2013b,c). All of these regional models were obtained by full-waveform inversion. For the majority of these regions, the CSEM mesh has been refined in the lat/lon direction to $50 \mathrm{~km}$. Within the Anatolian part of the Europe model, the mesh was further refined to $15 \mathrm{~km}$ in the horizontal direction, to respect the higher resolution in this region.

The $Q$ model of the CSEM is that given by PREM, and all moduli are stored at a reference frequency of $1 \mathrm{~Hz}$. This is in contrast to the $Q$ model used for the four aforementioned subregions, which was provided by QL6 (Durek \& Ekström 1996). This discrepancy in $Q$ leads to an unavoidable initial discrepancy in seismic velocities as well. This is removed, however, with global long-wavelength updates that establish a consistent common baseline for all regions. The details of the global updates are described in Section 3.2.

\section{WORKFLOW DESCRIPTION AND MODEL UPDATES}

The CSEM workflow is visualized in Fig. 3. First, a solver and discretization are selected, and a subregion is extracted from the current CSEM following the procedures outlined in Section 2.3.2. The choice of solver and discretization will depend on the available data, the computational resources and the geological question that motivates the specific tomographic study. For example, a study focused on strongly heterogeneous crustal structure may use fullwaveform inversion driven by numerical wave equation solvers, while one targeting the less heterogeneous mid-mantle structure may fare better with a ray-based traveltime tomography. Regardless of this choice, upon extraction the model is independent from the global CSEM, and is stored on the numerical grid of the chosen solver.

At this point, the selected inverse problem machinery is used to compute a regional-scale update. This will typically involve the collection of data, the solution of the forward problem, as well as single-step or iterative updates. The complete update, that is the new regional model minus the initial regional model from the earlier extraction, is then re-introduced into the CSEM. In addition to the reasons given in Section 2.3.1, updates (perturbations) instead of absolute models are reintroduced in order to mitigate the effect of solver biases, and to ensure that no bulk perturbations leak back into the global model. Following the same procedure, further subregions may be refined.

The addition of fine-scale regional structure will affect global structure through scale-coupling. For instance, refining the details crustal structure may modify the broad patterns of anisotropy in the mantle (Ferreira et al. 2010). To ensure that the updated subregions do not degrade but improve the quality of the global CSEM, globalscale updates are performed. These updates are based on a longperiod reference data set, described in Section 3.2.1, that should always be matched closely by synthetic seismograms, regardless of any regional-scale modifications. More information about global updating is given in Section 3.2.

\subsection{Regional updates}

In the next paragraphs, we describe three regional updates to the initial CSEM from Section 2.4 that follow the workflow outlined 


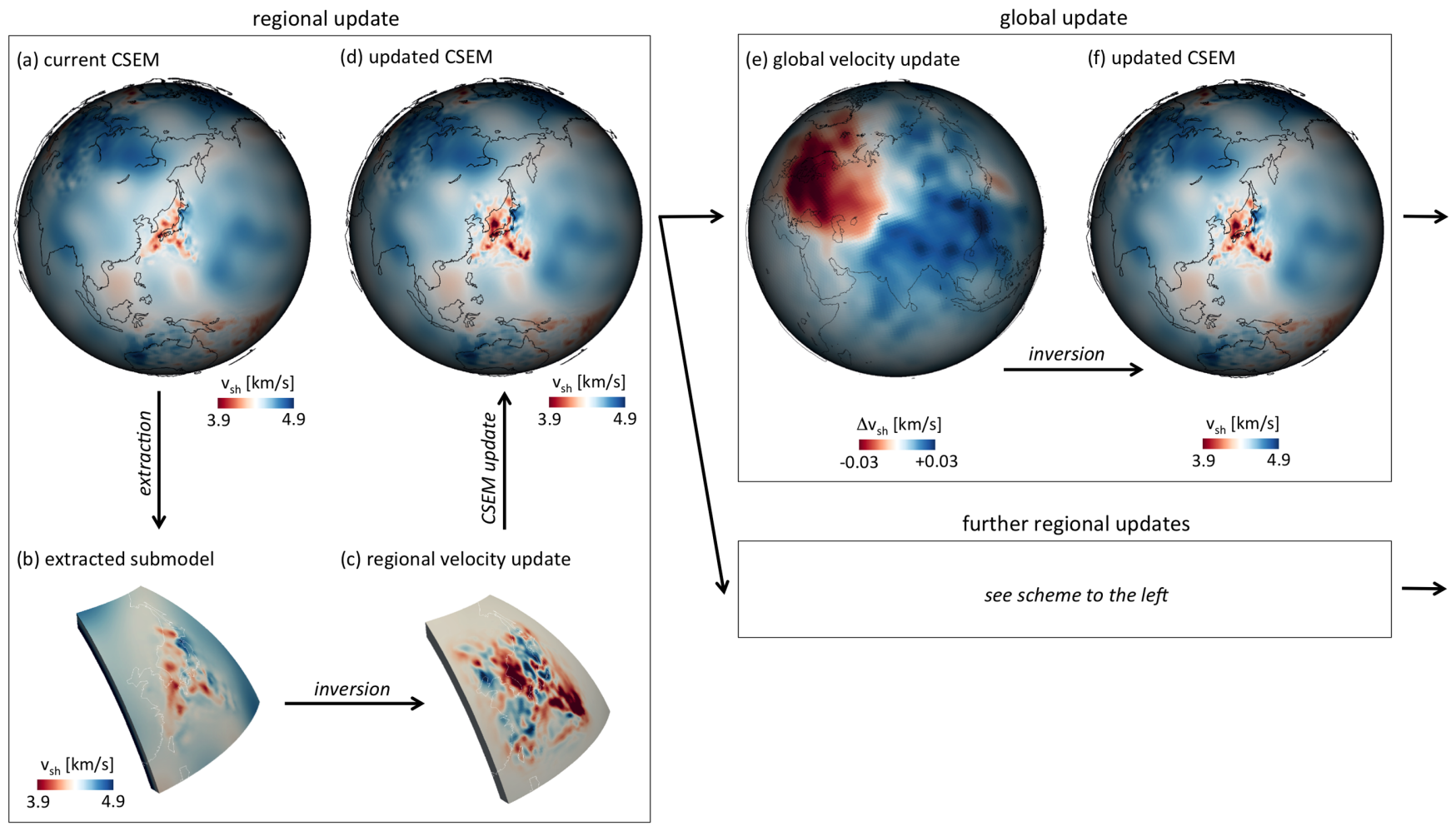

Figure 3. Schematic illustration of the workflow to update the CSEM. From the current CSEM (a), a subregion is extracted following the procedures outlined in Section 2.3.2. This subregion (b), then exists independently and may be updated using a generic set of forward and inverse routines. The updates to the initial subregion (c) are then added back to the global CSEM (d). The workflow may continue either with additional regional updates, or with a global full-waveform update that ensures consistency of the regional refinements with the global reference data set described in Section 3.2.1.

above. The updates of the Japanese Islands region and the Western Mediterranean are full-waveform inversions with synthetic seismograms calculated via the spectral element solver SES3D (Fichtner et al. 2009b; Gokhberg \& Fichtner 2015), sensitivity kernels calculated using adjoint techniques (e.g. Tarantola 1988; Tromp et al. 2005) and misfits based on time-frequency analysis (Fichtner et al. 2008). In contrast, the update of Europe was driven by a hybrid approach consisting of both ray-theoretical traveltime tomography based on a fast-marching method (Rawlinson \& Sambridge 2004; de Kool et al. 2006) and the aforementioned full-waveform inversion. The descriptions are brief, as each inversion will be covered with more detail in a future publication. In particular a complete discussion of model resolution is not included here, although in well-covered regions the resolution of the full-waveform models approaches the wavelengths of the shortest period data used in the inversion.

\subsubsection{Regional full-waveform update of Japan}

This study area, characterized by complex interactions between several tectonic plates, includes the Japanese Islands, Taiwan, the Korean peninsula, easternmost parts of China and Russia, Sakhalin and the majority of the Kuril Islands. A prominent subduction zone is formed between the Pacific plate and the overriding Okhotsk, Philippine Sea and Mariana plates, with another resulting from the subduction of the Philippine Sea beneath the Amur and Okinawa plates. In addition to notable surface expressions, subducted slabs have significant imprints on the mantle, including significant velocity contrasts between the slab and the surrounding mantle (Zhao
2004), induced flow in the mantle wedge (Anderson et al. 2004; Hoernle et al. 2008) and a lowered solidus of the mantle material, resulting in volcanism due to dehydration of the descending slab (Tatsumi 1989). These subduction zones and their effects on the mantle contribute to the complexity of the subsurface in the area. Due to this complexity, we use full-waveform inversion to derive an updated 3-D model. The initial model was extracted from the CSEM, with specific regional contributions from Diaz-Steptoe (2013).

We selected 58 earthquakes, distributed as uniformly as possible within the model domain, with magnitudes ranging between $M_{w}=5.0$ and 6.9. The waveform data were obtained from all freely available seismic networks in the area, namely the Full Range Seismograph Network of Japan (F-net), the Broad-band Array in Taiwan for Seismology, the Korean National Seismograph Network, the China National Seismic Network, the New China Digital Seismograph Network, the Global Seismograph Network and the Korean Seismic Network. With 165 available seismic stations and 58 events, our data set contains more than 5500 threecomponent waveforms. The data coverage are shown in the upper left panel of Fig. 4, and its processing and management was handled by the Large Scale Inversion Framework (LASIF; Krischer et al. 2015).

The inversion followed a multiscale approach, with iterations performed within different frequency bands. Beginning with longer periods, six iterations were performed in the period band of 50-80 s, with a total misfit reduction of 26.7 per cent. Another six iterations within the $30-80 \mathrm{~s}$ band reduced the misfit a further 19.5 per cent. Finally, seven iterations were performed with the $20-80 \mathrm{~s}$ band, with a total misfit reduction of 26.3 per cent. 

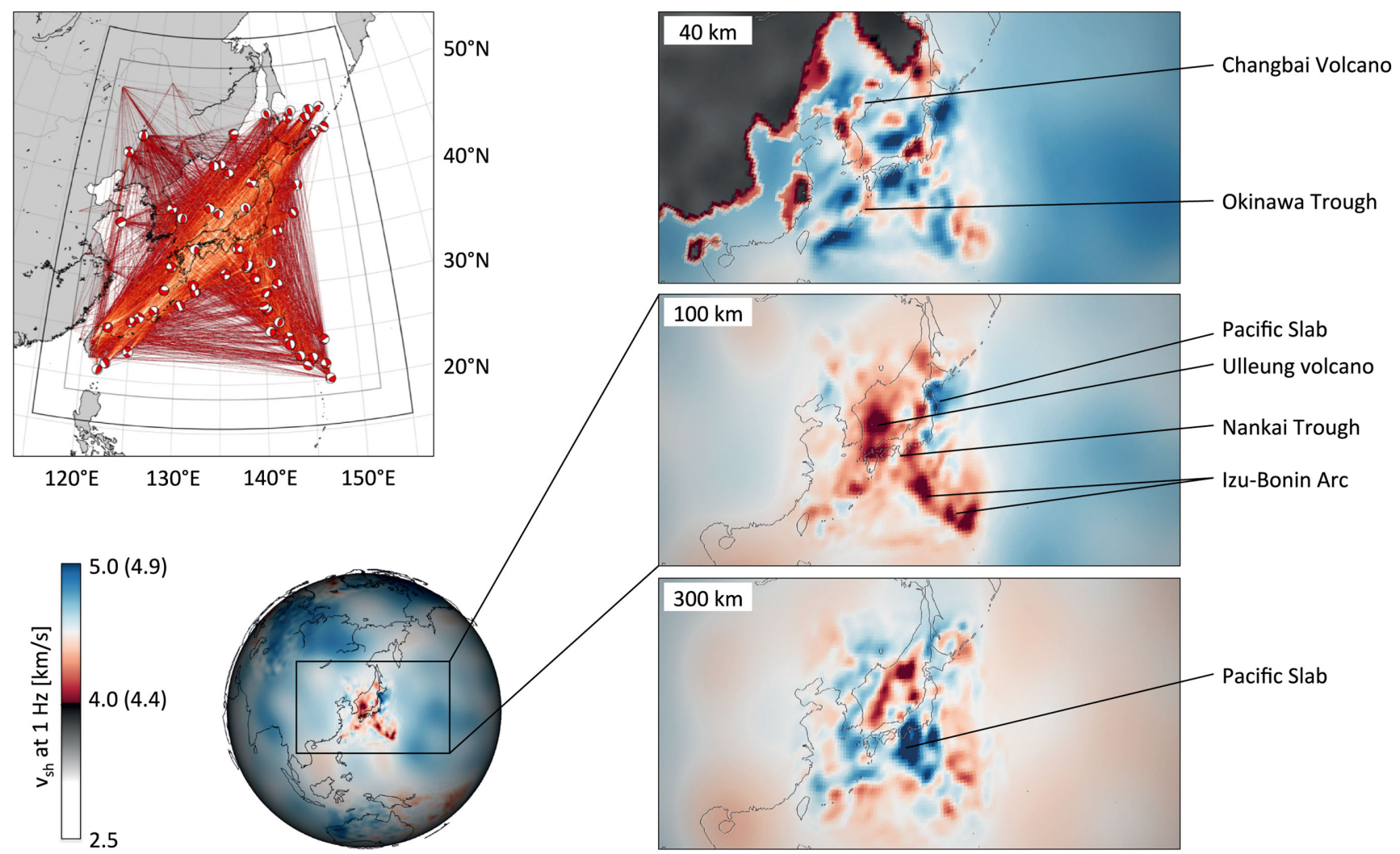

Figure 4. Refinement of the Japanese islands region. Surface projections of great-circle source-receiver paths as a proxy for geographic coverage are plotted in the top left corner. The depth slices show the distribution of $v_{\mathrm{sh}}$ at the reference frequency of $1 \mathrm{~Hz}$ at 40,100 and $300 \mathrm{~km}$ depth. Greyscale in the colourbar roughly represents crustal velocities from 2.5 to $4.0 \mathrm{~km} \mathrm{~s}^{-1}$. Mantle velocities from 4.0 to $5.0 \mathrm{~km} \mathrm{~s}^{-1}$ (4.4-4.9 $\mathrm{km} \mathrm{s}^{-1}$ for the $300 \mathrm{~km}$ slice) are shown in colours from red over white to blue. Specific geological features, such as the subducting Pacific Slab, the Izu-Bonin Volcanic Arc and several low-velocity zones that can be correlated with surface volcanism, are labeled. An overview of the data used in this inversion is given in Table 2 .

The final model shows expected features, such as high-velocity zones related to the subducted Pacific and Philippine Sea plates and low-velocity zones associated with the volcanic arcs. Furthermore, we detect a very strong low-velocity anomaly off the east coast of South Korea, located beneath Ulleung volcano. Horizontal slices through the final model can be seen in Fig. 4.

\subsubsection{Regional full-waveform update of the Western Mediterranean}

The evolution of the Mediterranean region over the past $50 \mathrm{Ma}$ is marked by the subduction of oceanic lithosphere in the context of the Africa-Eurasia convergence. While the geodynamics of the central and eastern Mediterranean are well understood (e.g. Faccenna et al. 2014), the development of the Western Mediterranean remains unclear. Subjects of ongoing debate include the extent of westward extension in the Alboran Sea, the physical mechanisms for the extension and formation of the Betic-Rif orogenic system and the existence of northward subduction beneath the Algerian coast. Here we use the opportunity provided by recent dense deployments of broad-band stations in the region to refine the Western Mediterranean crust and mantle structure of the CSEM.

The data used for this refinement are a compilation of threecomponent seismograms from earthquakes that occurred in the Mediterranean region. We obtained waveform data from IRIS (www.iris.edu) and ORFEUS (www.orfeus-eu.org), as well as from the temporary deployments of IberArray (Díaz et al. 2009), the PASSCAL experiment PICASSO and smaller arrays deployed by the Universities of Münster (Germany) and Bristol (UK). Our final data set contains 13, 089 three-component recordings from 52 events in the period range from 12 to $150 \mathrm{~s}$. A summary of the data coverage is shown in the upper left panel of Fig. 5.

We terminated the full-waveform inversion after 20 iterations, which is when the misfit reduction in one iteration dropped below 1 per cent. After iterations 5 and 15 we re-inverted for the source locations and origin times (Fichtner \& Villaseñor 2015). The total misfit reduction after 20 iteration was nearly 80 per cent.

An image showing the resolved structure in the region can be seen in Fig. 5. At crustal depths, the model features various lowvelocity sedimentary basins, including the Rhône Valley, as well as the Molasse, Po, Ebro, Tajo and Guadalquivir Basins. Around $40 \mathrm{~km}$ depth, the deep roots of the Alps, Dinarides, Pyrenees and the Betics are clearly visible. At $300 \mathrm{~km}$ depth, the high velocities of the Mediterranean slab system are the dominant feature. More details of the regional refinement in the Western Mediterranean, including an extensive resolution analysis, can be found in Fichtner \& Villaseñor (2015).

\subsubsection{Regional full-waveform and traveltime update of Europe}

Full-waveform inversion is limited to intermediate period bands by the finiteness of computational resources that prevent numerical modelling at arbitrarily short periods. This bias toward intermediate periods implies that surface waves tend to dominate regionalto global-scale full-waveform inversions. Body waves that are more prominent at high frequencies are mostly underrepresented, leading 

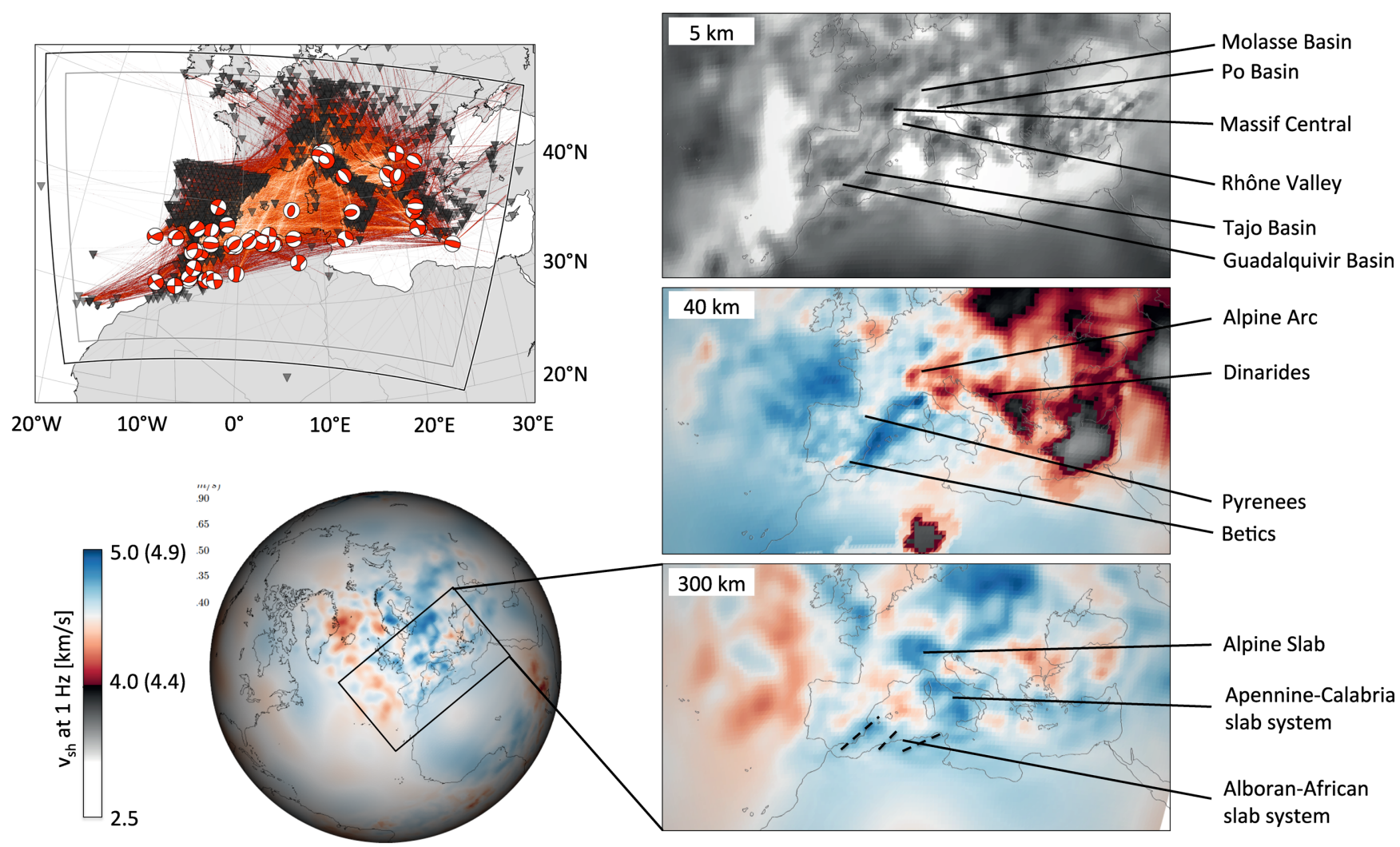

Figure 5. Refinement of the Western Mediterranean. Surface projections of great-circle source-receiver paths are plotted in the top-left corner. The depth slices show the distribution of $v_{\mathrm{sh}}$ at the reference frequency of $1 \mathrm{~Hz}$ at 5,40 and $300 \mathrm{~km}$ depth. Greyscale in the colourbar roughly represents crustal velocities from 2.5 to $4.0 \mathrm{~km} \mathrm{~s}^{-1}$. Mantle velocities from 4.0 to $5.0 \mathrm{~km} \mathrm{~s}^{-1}\left(4.4-4.9 \mathrm{~km} \mathrm{~s}^{-1}\right.$ for the $300 \mathrm{~km}$ slice) are shown in colours from red over white to blue. Specific geological features, labeled in the figure, include various low-velocity sedimentary basins at $5 \mathrm{~km}$ depth, the deep crustal roots of the Alps, Dinarides, Pyrenees and the Betics, as well as the Alboran-African and Alpine-Apennine-Calabria Slab systems. An overview of the data used in this inversion is given in Table 2 .

to poor resolution below $\sim 300 \mathrm{~km}$ depth. In contrast, traveltime tomography based on ray theory naturally incorporates information from high-frequency body waves. Here we use the CSEM framework to combine full-waveform inversion and traveltime tomography in order to broaden the exploitable bandwidth.

Following the extraction of the submodel comprising Europe and Western Asia, we alternated traveltime tomography and fullwaveform inversion with the goal of jointly explaining both data sets. The full-waveform updates were based on a subset of the 52 events used by Fichtner et al. (2013c), resulting in 13, 086 seismograms filtered between 40 and $100 \mathrm{~s}$. The inversion scheme, including forward modelling and iterative misfit minimization, was the same as for the regional updates in Japan and the Western Mediterranean, described in the previous paragraphs. For the traveltime tomography we used $19,014 S$-wave traveltime picks from 710 events within the study region, compiled by the International Seismological Centre (International Seismological Centre 2012). Since $S$-wave traveltimes were measured on the transverse ( $\mathrm{SH}$ ) component, we only updated the SH velocity model. The source-receiver distribution for the traveltime tomography is shown in Fig. 6(a).

The inversion consisted of alternating updates, from both traveltime tomography and full-waveform inversion. Each method was iterated until the misfit was suitably reduced. Subsequently, the updated model was reintroduced into the CSEM, and then again extracted onto the numerical grid of the next method. In total, we performed two alternating traveltime and full-waveform updates. Upon completion, the rms traveltime misfit had decreased by
27 per cent and the waveform misfit had decreased by 43 per cent. Fig. 6(b) summarizes the combined inversion procedure from the perspective of the waveform misfit.

The effect of incorporating short-period body wave traveltimes into the intermediate-period full-waveform inversion are illustrated in Fig. 7, which shows European mantle structure in the initial CSEM (left) and following the alternating inversion (right). While $\mathrm{SH}$ velocity heterogeneities in the initial model are mostly less than $\pm 0.1 \mathrm{~km} \mathrm{~s}^{-1}$ below 400 depth, variations around $\pm 0.2 \mathrm{~km} \mathrm{~s}^{-1}$ appear in the update.

Along with the new structural insights gained, this inversion also served to test the technical workings of the CSEM. As indicated by Fig. 6(b), the change in waveform misfit introduced by swapping a waveform-based paradigm for a traveltime-based paradigm has a minimal effect. While this is partly due to careful experimental design - the traveltimes were explicitly chosen to have little sensitivity to regions well covered by waveforms-it suggests that inversions respecting different approximations to the wave equation can coexist in a single model without detrimental effects.

\subsection{Global updates and the reference data set}

Regional refinements introduce small-scale features that affect images of large-scale structure. For instance, the appearance of a low-velocity sedimentary basin in a regional submodel will delay teleseismic body waves recorded in the basin area, and thereby 
(a) Source-receiver distribution

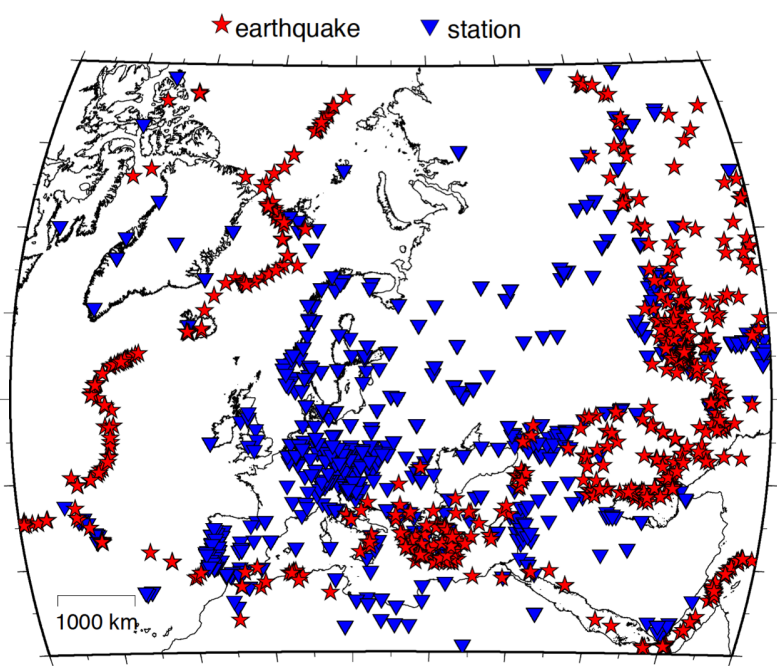

(b) Waveform misfit evolution

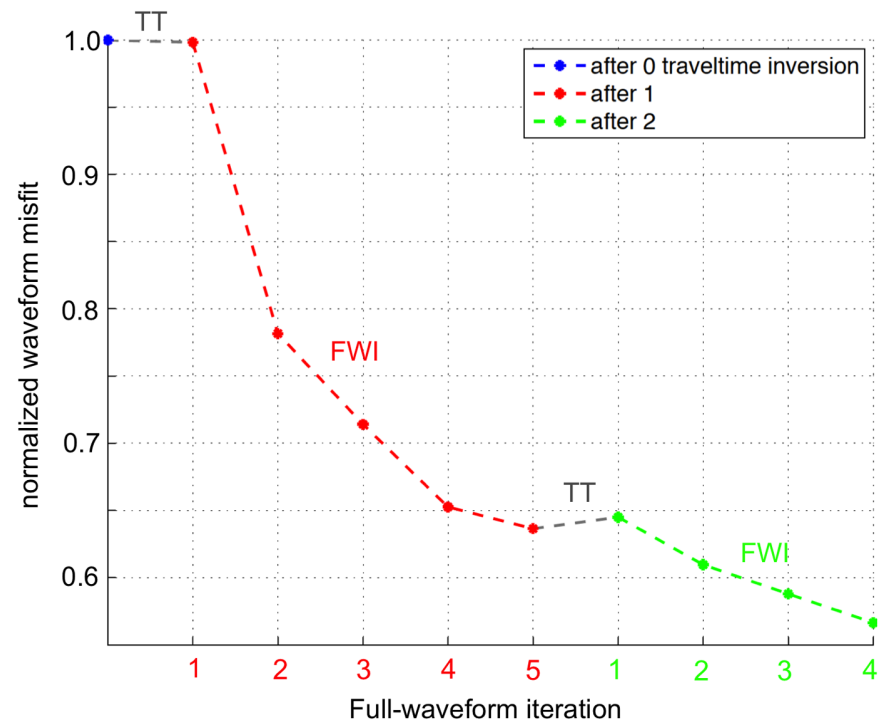

Figure 6. Combined traveltime tomography and full-waveform inversion. (a) Geographic distribution of sources (red stars) and receivers (blue triangles) used in the traveltime tomography. Details on the data coverage in the full-waveform inversion part can be found in Fichtner et al. (2013c). (b) Evolution of the waveform misfit during the combined inversion. Starting from a normalized misfit of 1, the first traveltime tomography, labeled 'TT', hardly changed the waveform misfit, indicating that the traveltimes are complementary to the waveforms. This was followed by five full-waveform inversion iterations, indicated in red. The same sequence of traveltime tomography and full-waveform inversion was then repeated. At the end of the combined inversion procedure, the traveltime and waveform misfits decreased by 27 per cent and 43 per cent, respectively.
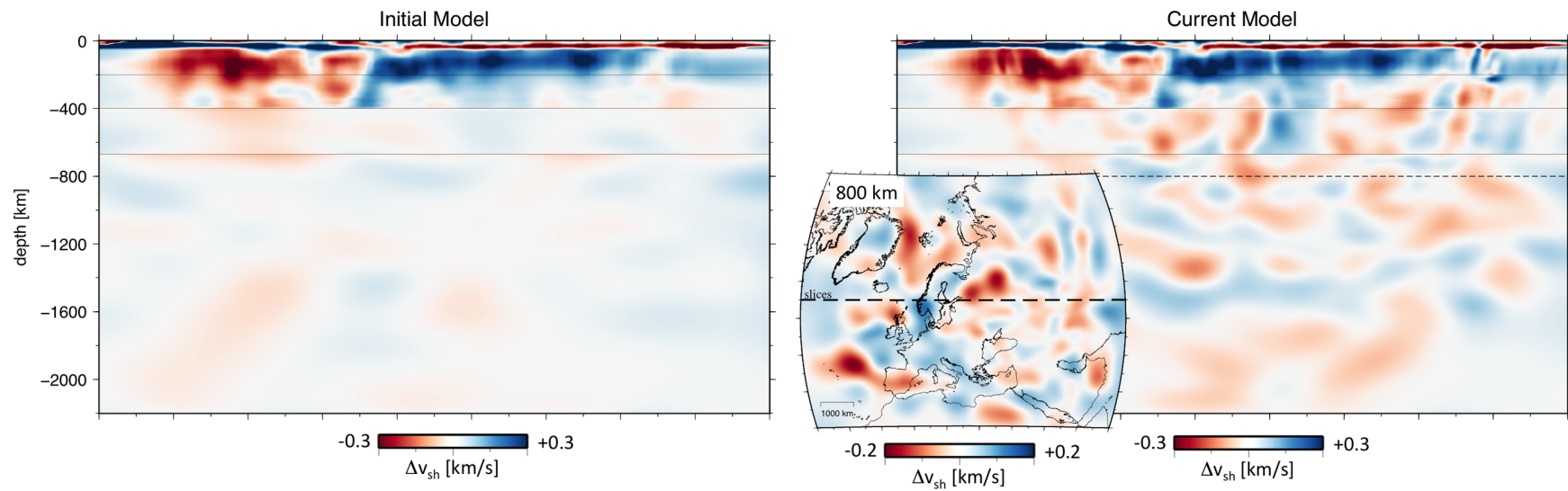

Figure 7. SH velocity structure in the initial model (left) and in the final model after the combined full-waveform and traveltime inversion (right). The dashed line in the horizontal slice at $800 \mathrm{~km}$ depth indicated the position of the vertical profiles. An overview of the data used in this inversion is given in Table 2.

influence the model at greater depth in the mantle. Similarly, newly introduced details of crustal structure will affect images of largescale anisotropy in the mantle. To properly account for these scalecoupling effects, and to ensure that regional updates remain consistent with a global reference data set, we perform full-waveform inversions also for the whole Earth.

At this early stage of the CSEM development, the global inversion is also intended to reverse any malignant artefacts arising from the compilation of the initial CSEM, described earlier in Section 2.4. These artefacts may be related to different $Q$ models used in the regional inversions, or to the smoothing applied in order to seamlessly integrate the submodels in the background structure derived from S20RTS (Ritsema et al. 2004).

In the following paragraphs, we describe the global fullwaveform inversion, including details on the reference data set, forward and adjoint modelling and the nature of the first global updates.

\subsubsection{Reference data set}

The reference data set is a collection of seismic data that should generally be well explained by the CSEM, in particular following regional updates. It currently consists of three-component recordings from 225 globally distributed earthquakes that occurred between 2008 and 2013. The magnitude range $M_{w}=5.5-6.7$ was chosen to exclude events which are too weak to be recorded cleanly on the global scale, as well as larger events for which finite-source effects may be important. All waveforms were recorded by the CI, IC, II and IU networks, and obtained from IRIS (www.iris.edu) using ObsPy (Beyreuther et al. 2010; Megies et al. 2011). A map of the earthquakes and stations used for the reference data set is shown in Fig. 8 .

We organized and processed the data using the LASIF (Krischer et al. 2015). This preprocessing served to remove the instrument response, and to bandpass filter to periods between 60 and $120 \mathrm{~s}$. 


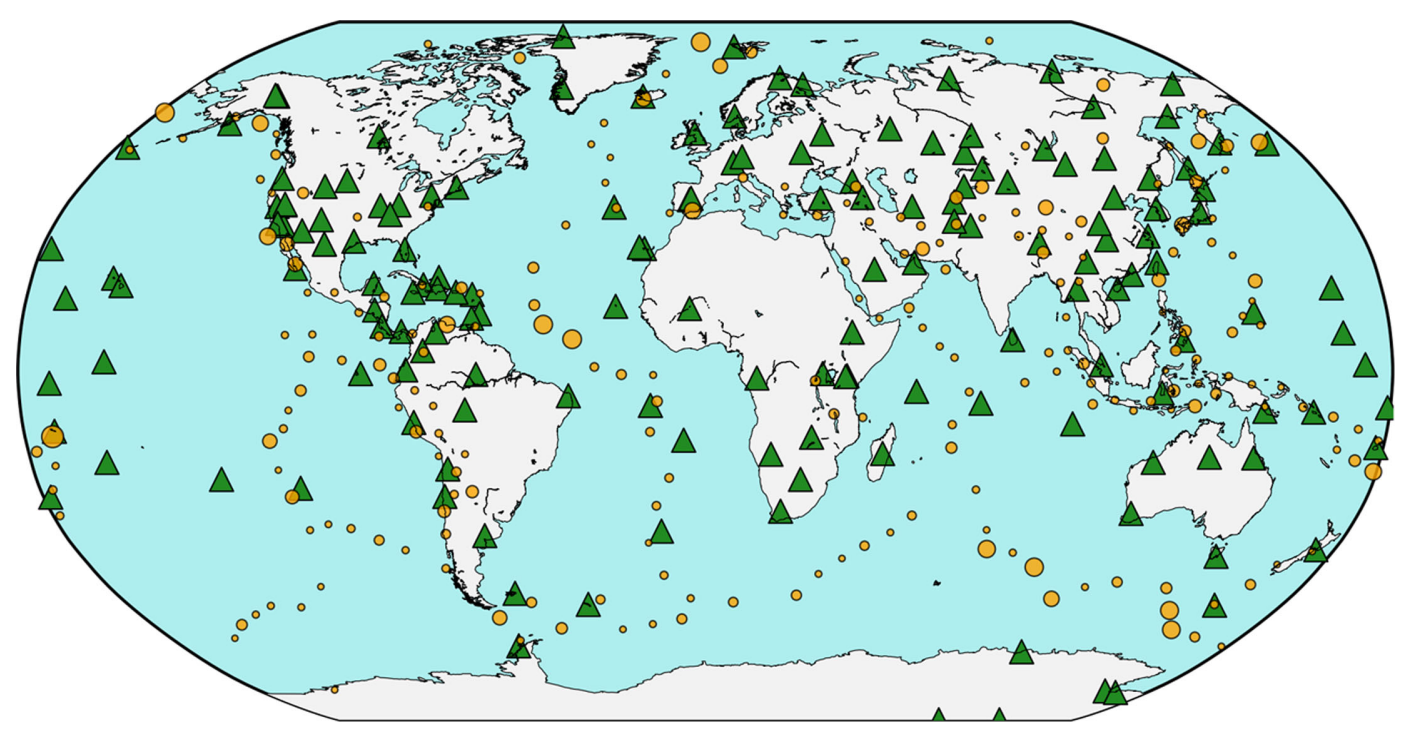

Figure 8. Source-receiver distribution of the reference data set used in the global full-waveform inversion. Earthquake epicentres are marked by circles with variable size that indicates magnitude, ranging from $M_{w}=5.5$ to 6.7. All stations (triangles) belong to the GSN meta-network.

These filtering parameters were chosen to select only those data which were sensitive to large scale Earth structure. Future extensions of the reference data set will include a broadening of the period range, as well as the incorporation of ambient noise correlations (see Section 4.2 for details).

\subsubsection{Forward modelling and misfit quantification}

To solve the wave equation on the global scale, we use the GPU accelerated spectral-element solver SPECFEM3D_GLOBE (Komatitsch et al. 2010; Komatitsch 2011). In the modelling we consider the effects of surface topography, self-gravitation, oceanic loading, ellipciticy and viscoelasticity. For our specific case, the element size is $\sim 80 \mathrm{~km}$ at the surface, which translates to $\sim 1.5$ elements per wavelength for periods above $60 \mathrm{~s}$. To capture the information contained in both minor- and major-arc surface waves, the wavefield was simulated for $90 \mathrm{~min}$. The Earth model used in these simulations was extracted from the CSEM, following the procedure outlined in Section 2.3.2.

The forward simulations were run on the heterogeneous computing cluster Piz Daint, located at the Swiss National Supercomputing Centre (CSCS). With GPU acceleration, each event simulation consumed approximately 6 node hours of compute time, for 1350 node hours in total. This translates into approximately 15 min of wall time per event.

To quantify the misfit between observed and synthetic seismograms, we use time-frequency phase misfits (Fichtner et al. 2008). To mitigate the non-linear nature of this measurement, we only consider time windows where the synthetic and observed data are sufficiently in phase. Using LASIF, we automatically select $\sim 44000$ variable length windows, within which the time-frequency misfit is calculated. These windows were distributed over $\sim 19000$ seismograms.

\subsubsection{Calculating and interpreting the gradient}

To efficiently compute a model update, we employ adjoint techniques to calculate the misfit gradient for each event (e.g. Tarantola
1984; Pratt 1999; Fichtner et al. 2006; Komatitsch et al. 2015). Summing all individual event gradients yields the cumulative misfit kernel for all source-receiver pairs. Due to the sparse and uneven source-receiver distribution, we aggressively smoothed the cumulative gradient using an elliptical Gaussian smoothing kernel, with a variance of $250 \mathrm{~km}$ horizontally, $5 \mathrm{~km}$ radially and tapered out the update gradually above $80 \mathrm{~km}$ in depth. This aggressive smoothing is primarily intended to remove long-wavelength artefacts from the assembly of the initial CSEM.

An image of the smoothed gradient for the first iteration of the global full-waveform inversion, along with two real and synthetic seismogram examples, is shown in Fig. 9. Notable features include broad negative contributions beneath Europe and Japan, indicating that the initial CSEM in these regions is too slow. An inspection of recordings from Europe and Japan confirms this observation: surface waves calculated using the initial CSEM arrive $\sim 30$ s late.

To some extent, these long-wavelength discrepancies result from the construction process of the initial CSEM, during which various submodels with different 1-D backgrounds and different $Q$ models were assembled into one global model (see Section 2.4). Beneath Central/Eastern Europe, negative contributions in the gradient also result from insufficient coverage of the high-velocity East European Craton in the regional tomography that contributed to the initial CSEM (Fichtner et al. 2013c).

After two iterations on the global scale, the largest changes to the initial CSEM amounted to $\sim 1$ per cent in $S$ velocity. They mostly act to remove artefacts from the construction of the initial CSEM, and to improve poorly covered regions.

\subsubsection{Misfit reduction}

These first global iterations are special because the initial CSEM was assembled from various submodels without direct reference to data. We therefore expected that long-wavelength improvements would be required. The first iteration reduced the total misfit across the initially selected 43758 windows by $\sim 16$ per cent. For the second iteration, we automatically reselected the measurement windows, and, due to the improved model, 46385 windows passed. We then recalculated the gradient using the updated windows and model, and 


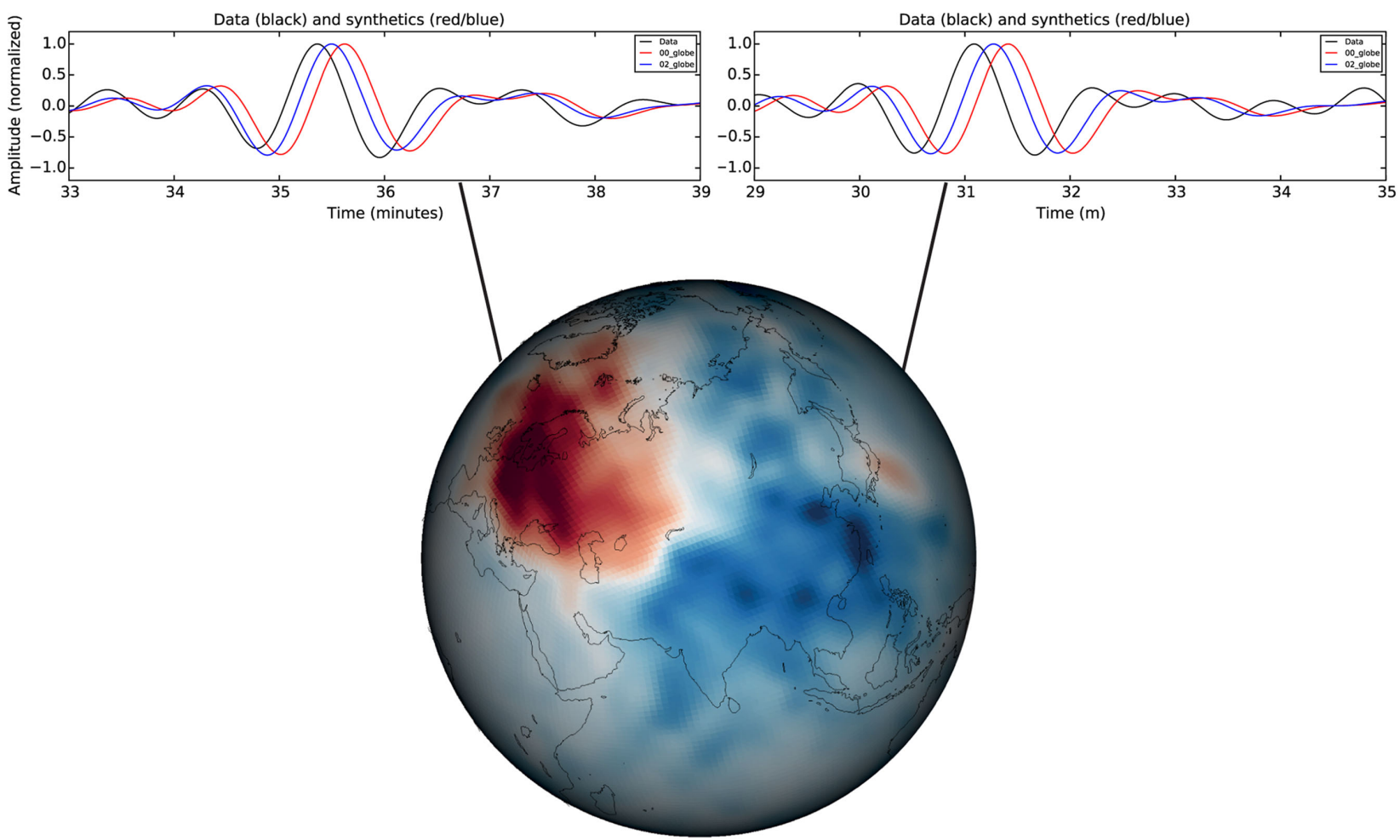

Figure 9. Illustration of the $v_{\text {sh }}$ gradient from the first iteration of the global full-waveform inversion, plotted at $100 \mathrm{~km}$ depth. The colour scale indicates the direction of the update. While adjustments toward higher $v_{\mathrm{sh}}$ appear beneath Europe and Japan, $v_{\mathrm{sh}}$ is reduced in South-East Asia. At this early stage of the CSEM evolution, these long-wavelength updates mostly act to remove artefacts from the assembly of the initial CSEM, which are related to different reference and attenuation models of the various subregions. Furthermore, the broad updates contribute new structure in parts of the globe that were poorly covered in the earlier regional inversions, including, for instance, the East European Platform. Seismogram examples from Europe (II.OBN.BHZ) and Japan (II.ESK.BHZ) are presented in the top panels. Shown are the observed seismograms (black), as well as synthetic seismograms for the initial CSEM (red) and after two steepest-descent iterations (blue). The waveform fit is significantly improved.

an additional steepest-descent iteration further reduced the misfit by $\sim 9$ per cent. Randomly selected comparisons between observed and synthetic seismograms, using the initial CSEM and the global update, are given in Fig. 10. An encouraging fit is seen between observations and synthetics, with the fit visually improving as the iterations progress.

\section{DISCUSSION AND OUTLOOK}

In the following paragraphs, we provide a summary of the current CSEM, in terms of both assimilated data and represented Earth structure. We furthermore discuss an independent assessment based on a qualitative comparison of teleseismic ambient noise correlations and numerical Green functions. Finally, we present possible directions of future research and the envisioned evolution of the CSEM.

\subsection{Presentation of the current CSEM}

Table 2 provides a summary of the data used in the construction of the current CSEM, excluding those employed in the development of the initial 1-D background PREM (Dziewoński \& Anderson 1981), the 3-D background S20RTS (Ritsema et al. 2004) and the initial crustal model (Meier et al. 2007a,b). The average epicentral distances of the (sub)regions vary between $\sim 300$ and $\sim 10000 \mathrm{~km}$ and the periods of the full-waveform updates range from 8 to $200 \mathrm{~s}$. Regional updates that are currently under development include the
Sea of Marmara, the Iberian Peninsula, Jakarta, North America and the East African Rift System.

With our current focus being on the development of the CSEM as a computational framework, we limit our presentation of Earth structure in the current version to a brief tour of large-scale features. Several geological structures on the $10-100 \mathrm{~km}$ scale have been presented earlier in Sections 3.1.1 and 3.1.2. Fig. 11 shows the distribution of $v_{\mathrm{sh}}$ at the reference frequency $1 \mathrm{~Hz}$ and at $100 \mathrm{~km}$ depth. In the following paragraphs, we tour the model, focusing on some well-resolved larger-scale structures.

Fig. 11(a) is focused on the Atlantic Ocean, illustrating the contributions from the subregion models of Europe and the South Atlantic. Dominating the northernmost part of this model is the Iceland plume system, which expresses itself as a reduction in SH velocity beneath and around Iceland. Moving into northern Europe, we see a strong increase in $v_{\mathrm{sh}}$, extending from Scandinavia eastwards; this is the signature of the East European Craton. It is bordered to the east by the Tornquist-Teisseyre Line (TTL), which separates the platform from the tectonically active central and western Europe, which is marked by low velocities related to the Africa-Europe convergence. This broad suture zone encompasses northern Anatolia, the Pannonian Basin, the Dinarides and the Alpine belt. South of the TTL, under the Mediterranean, the subducting Hellenic Slab is apparent as a zone of high velocity.

Moving into Africa, we see the clear low-velocity signature of the Afar Rift Zone. Another low-velocity anomaly is present in the Cameroon Volcanic Line, extending from north-central Africa southwest to the Atlantic. The central and southern regions of 

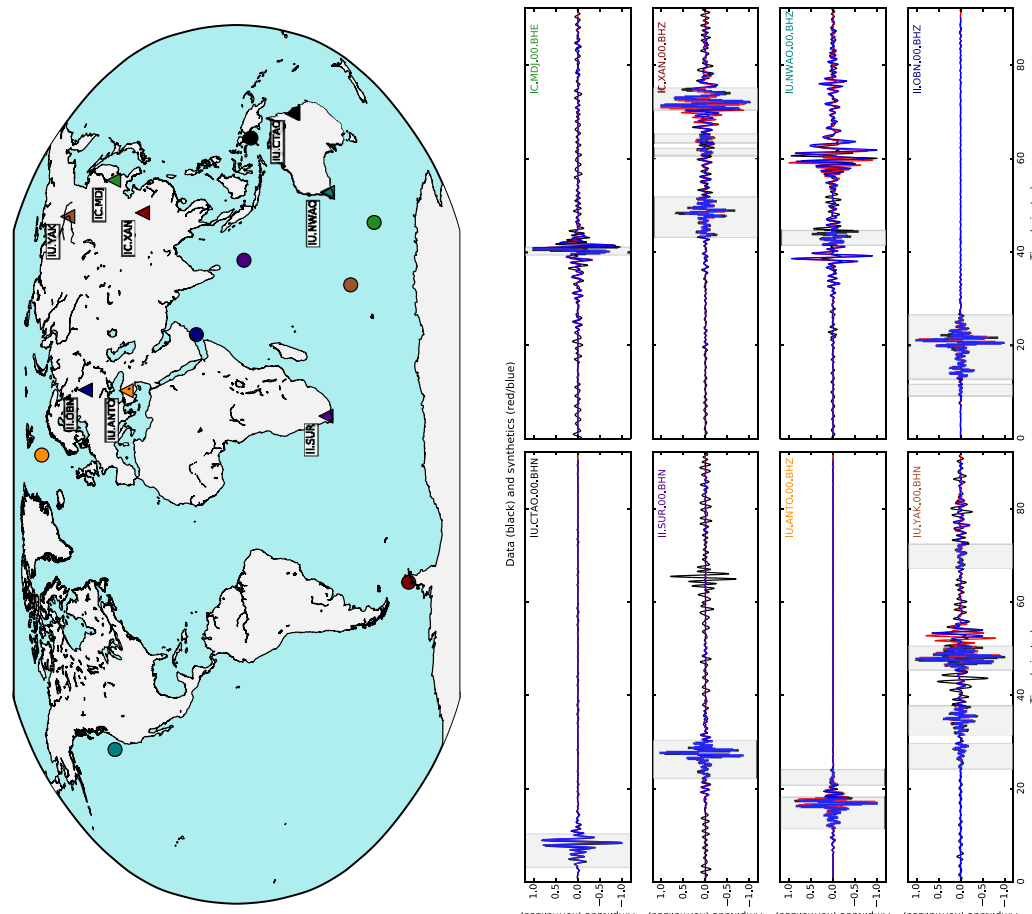

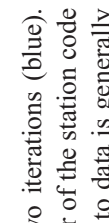

言要

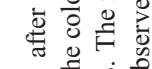

당

늠

可 氜 믄

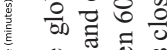

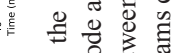

च

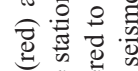

$\sum \stackrel{5}{0}$

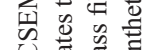

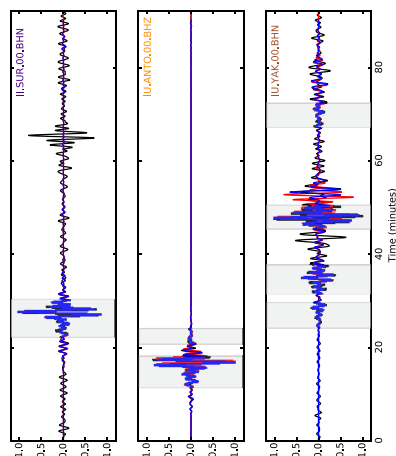

]

手政

ङ

苛

n

额

要

क छ

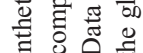

की
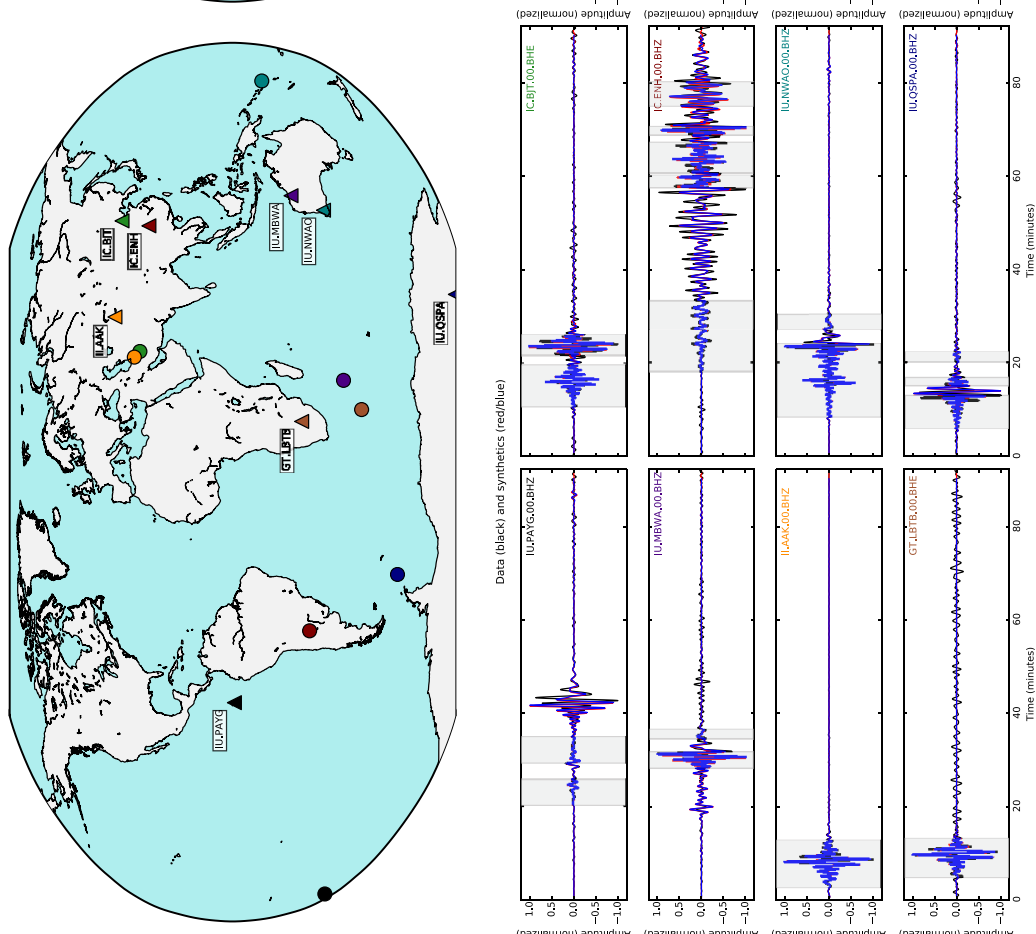

ज.

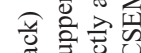

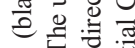

党

言㝕芯寻

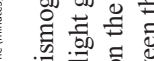

$\frac{n}{0}=5$

उ.

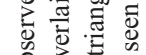

००

可

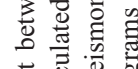

过

윰 च :

of

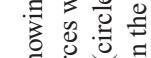

क力

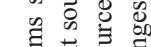

馬 苛

일

营 $\frac{0}{0}$.

उ

造造宽

文令吾黄

을 히응

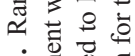

일

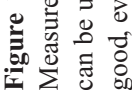


Table 2. Summary of subregions and data currently incorporated into the CSEM. Not listed are the data employed in the development of the initial 3-D background S20RTS (Ritsema et al. 2004) and the initial crustal model (Meier et al. 2007a,b).

\begin{tabular}{lccc}
\hline Region & Number (type) of recordings & Period band & Average epicentral distance \\
\hline Australia & $\sim 3000$ (complete waveforms) & $30-150 \mathrm{~s}$ & $\sim 2000 \mathrm{~km}$ \\
Europe & $\sim 15000$ (complete waveforms) & $30-200 \mathrm{~s}$ & $\sim 1500 \mathrm{~km}$ \\
Europe & $\sim 19000$ (SH wave traveltimes) & $\sim 5 \mathrm{~s}$ & $\sim 1500 \mathrm{~km}$ \\
Anatolia & $\sim 2300$ (complete waveforms) & $8-50 \mathrm{~s}$ & $\sim 300 \mathrm{~km}$ \\
South Atlantic & $\sim 4000$ (complete waveforms) & $50-120 \mathrm{~s}$ & $\sim 3000 \mathrm{~km}$ \\
Japan & $\sim 5500$ (complete waveforms) & $20-80 \mathrm{~s}$ & $\sim 1000 \mathrm{~km}$ \\
Western Mediterranean & $\sim 13000$ (complete waveforms) & $12-150 \mathrm{~s}$ & $\sim 500 \mathrm{~km}$ \\
Globe & $\sim 19000$ (complete waveforms) & $60-120 \mathrm{~s}$ & $\sim 10000 \mathrm{~km}$ \\
\hline
\end{tabular}

the continent are dominated by the high-velocity signatures of the Congo and Kalahari Cratons, respectively. In the South Atlantic, the Mid-Atlantic Ridge is the most prominent feature, although several low-velocity features can be seen extending perpendicular to its strike. These can be correlated with the surface expressions of the Walvis Ridge, extending towards Africa and the Rio Grande Ridge, extending towards South America (Colli et al. 2013). Finishing our tour of Fig. 11(a) by moving into South America, we can see two prominent high-velocity features, which are associated with the São Francisco and Amazonia Cratons, respectively.

Turning to Fig. 11(b), we focus on Asia and Oceania. Near Japan, the pronounced backarc basin underlying the Sea of Japan is contrasted with the high velocities resulting from the subduction of the Pacific plate. Additionally, we can see the low velocities of the Shikoku Basin, lying just seaward of the Nankai Trough. Extending southeast is a linear trend of low velocity, likely associated with the Izu-Bonin Volcanic Arc. Further south, we see the low velocities of the Lau Basin, broken by the Lord Howe Rise. Inland, a sharp velocity gradient, the Tasman Line, marks the transition from Phanerozoic to Precambrian Australia. Moving east, we see the lowvelocity sediments covering the Curnamona Block, along with the high velocities of the Gawler Craton. Along the east coast lies the Yilgarn and Pilbara Blocks, making up the West Australian Craton, with the Kimberly Block lying to the northeast. Continuing clockwise, we can see the broad low-velocity signature of the Tibetan Plateau, and finally the failed Baikal Rift.

\subsection{Independent validation via noise cross-correlation}

The cross-correlation of ambient seismic noise between two stations will, given idealized assumptions such as a uniform distribution of noise sources or equipartitioning, equal the Green function between the two stations (e.g. Lobkis \& Weaver 2001; Malcolm et al. 2004; Wapenaar 2004; Weaver \& Lobkis 2004; Wapenaar \& Fokkema 2006; Tsai 2010). Here we compare the causal branches of teleseismic ambient noise cross-correlations for two reference receivers in Australia and Europe, with synthetic Green functions. We calculated Green functions by modelling a vertical point source using SPECFEM3D_GLOBE (e.g. Komatitsch \& Tromp 2002a,b) with the current CSEM as a model, and the data and synthetics were bandpass filtered between 60 and 120 s. For simplicity, we concentrate only on the vertical component, and report qualitatively on their comparisons. These comparisons can be seen in Fig. 12, along with a map of the stations used.

In general, where noise correlations rise above the noise level, we see good agreement between observed correlations and synthetic Green functions. In this period band, the body wave correlations do not exceed the noise level, and should not be interpreted. The goal of inspecting the correlations was to qualitatively verify the global waveform fit with independent information. In the future, we plan to incorporate noise correlations into the global reference data set in order to improve coverage. Exploiting complete waveform in noise correlations may, however, require that the heterogeneous noise source distribution be taken into account, as recently proposed by various authors (Tromp et al. 2010; Hanasoge 2013a,b; Fichtner 2014).

\subsection{Towards a global high-resolution model}

The eventual goal of the CSEM is to present a high-resolution elastic model of the entire globe. While this ambition is not new, we believe that the philosophy and usability of the CSEM make it particularly well suited for this task. Perhaps the greatest practical strength of the workflow lies in the delegation of workload, that is the ability to involve more than one research group in the successive refinement of the model.

The CSEM attempts to tackle the growing mountain of available waveform data by building an Earth model piece by piece, one subregion at a time. This has great practical implications when considering the finite bandwidth of waveform sensitivity kernels. Since the resolution of seismic waveform inversions are closely tied to the bandwidth of the included data, it is desirable to invert for short periods. Unfortunately, the volume of the waveform sensitivity kernels are dependent on this frequency content, and asymptotically collapses to the infinitely thin ray path as periods decrease. Thus, in addition to the increase in computational effort needed to model shorter periods, incorporating shorter periods also increases the amount of data needed to fill a given volume with sensitivity. While this is possible on the regional scale, it may require the inclusion of millions of seismograms on the global scale (Schaeffer \& Lebedev 2013), which is currently beyond the reach of 3-D full-waveform inversion.

As stated in the Introduction, seismic models represent an image of the Earth filtered through the data set used in the construction of the model. This is one of many reasons why Earth models differ from one another. The CSEM sidesteps this problem by supporting the recursive inversion of subregions. Examples of this process can be seen in Sections 3.1.2 and 3.1.3. In the first example, a new, higher resolution subregion was created within the European subregion, which was already stored at a higher resolution than the global background. Due to the size of this subregion, its source-receiver coverage, and its unique data set, the resolution in this particular location was able to exceed that of the European starting model. As more data become available within Europe, further inversions may be performed, using the nested high-resolution subregions as a starting model. In the second example, entirely different forward and 

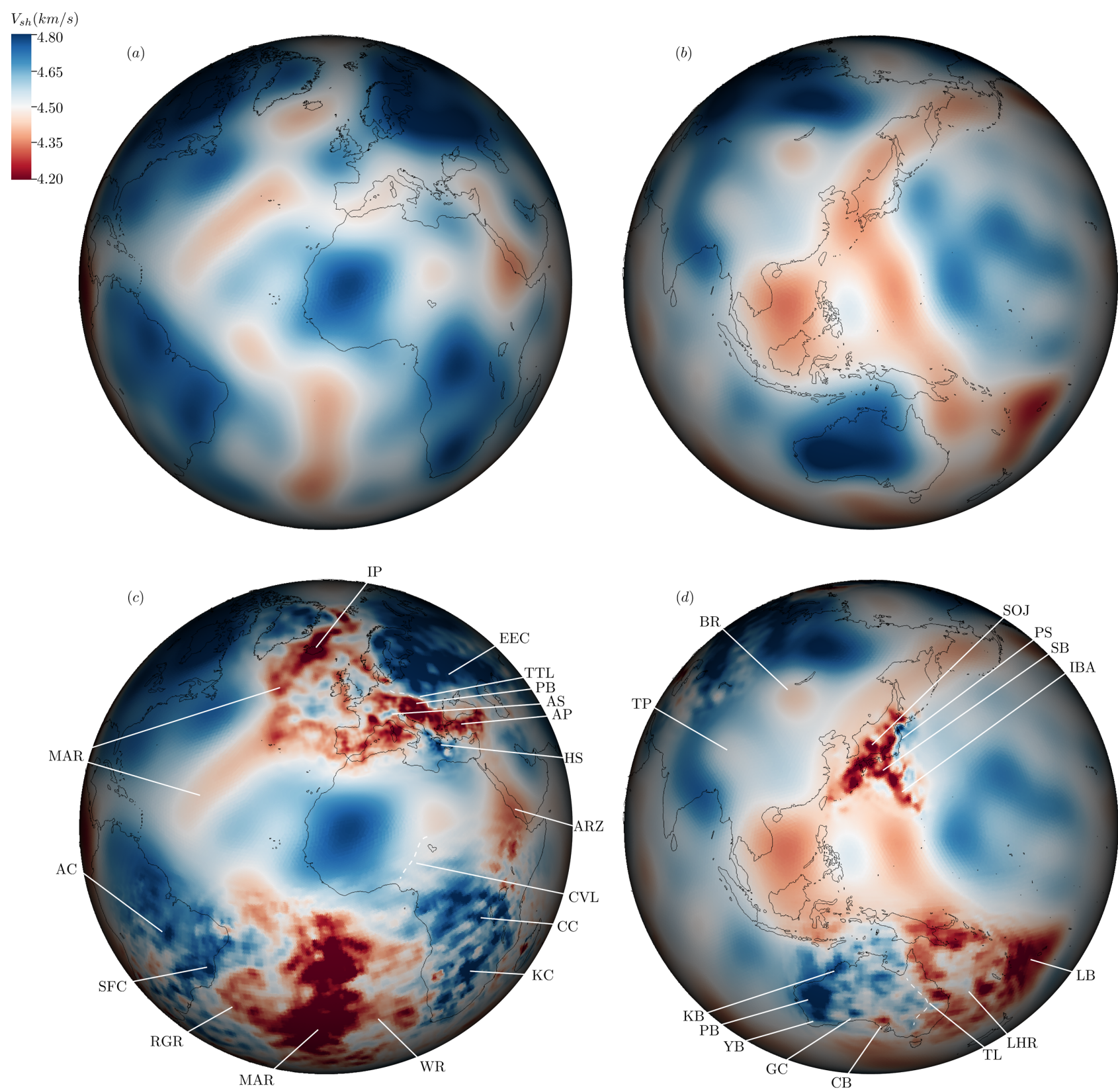

Figure 11. An image of $v_{\mathrm{sh}}$ at a depth of $100 \mathrm{~km}$. Images (a) and (b) show details present in the starting model, while (c) and (d) show the new details resulting from the addition of high-resolution subregions. A subjectively chosen collection of features is labeled. In (c): AC, Amazonia Craton; AP, Anatolian Plateau; ARZ, Afar Rift Zone; AS, Alpine Slab; CC, Congo Craton; CVL, Cameroon Volcanic Line; EEC, East European Craton; HS, Hellenic Slab; IP, Iceland Plume; KC, Kalahari Craton; MAR, Mid-Atlantic Ridge; PB, Pannonian Basin; RGR, Rio Grande Ridge; SFC, São Francisco Craton; TTL, Tornquist-Teisseyre Line; WR, Walvis Ridge; In (d): BR, Baikal Rift; CB, Curnamona Block; GC, Gawler Craton; IBA, Izu-Bonin Arc; KB, Kimberly Block; LB, Lau Basin; LHR, Lord Howe Rise; PB, Pilbara Block; PS, Pacifc-plate subduction; SB, Shikoku Basin; SOJ, Sea of Japan; TL, Tasman Line; TP, Tibetan Plateau; YB, Yilgarn Block.

inverse techniques were used to extract information about the deep structure of Europe, using data which probed regions inaccessible to the original regional full-waveform inversion. By recursively inverting regions across the globe, at different scales and using different techniques and data sets, we hope to remain data-agnostic. Of course, we cannot sidestep the subjectivity introduced by regularization, but here we again defer to the global full-waveform inversion of the reference data set, and allow it to automatically fix any malignancies that would act to degrade the global waveform misfit.

Of course, with talk of resolution also comes talk of its quantification, and it is here that the CSEM currently falls short.
While resolution in individual subregions may be quantified during their respective refinements, this quantification becomes invalid following the next global update. Moving towards a comprehensive picture of global resolution is a topic for future work.

\subsection{Homogenization and upscaling}

Currently, elastic parameters are extracted from and interpolated onto the CSEM by means of simple first-order interpolation techniques, regardless of scale. Since the highest resolution of the stored models $(\sim 15 \mathrm{~km})$ is on the same order as the spatial discretization of the forward solvers, errors stemming from these simple 


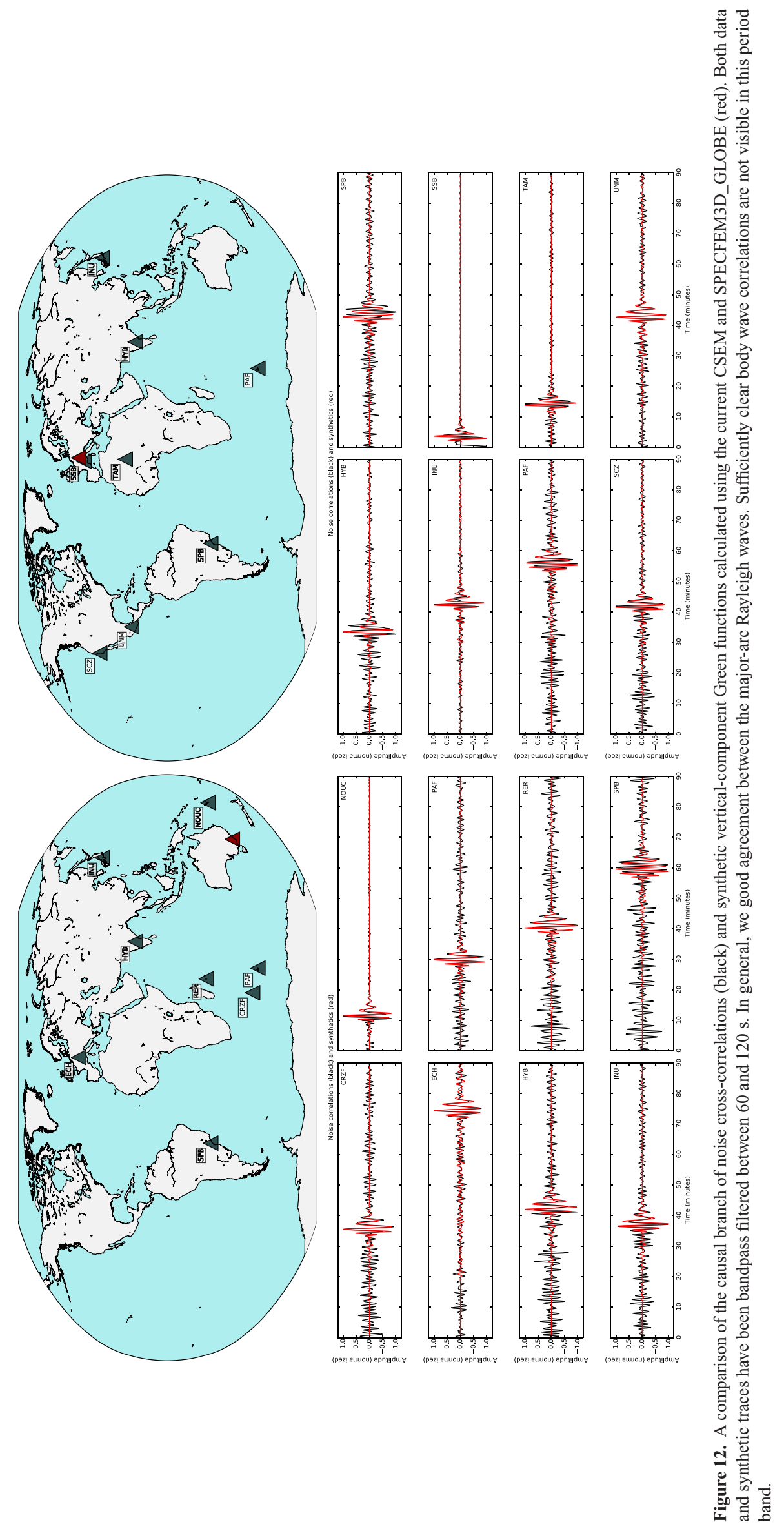


interpolation techniques are practically negligible. This is not expected to be the case as the model develops. As subregions, which may have resolution lengths finer than the grid resolution of subsequent extractions, are added to the CSEM, more sophisticated techniques should be used to ensure that fine-scale structure is accurately accounted for.

A possible solution is to employ homogenization techniques (Capdeville et al. 2010a, 2015; Capdeville \& Cance 2015), which calculate a long-wavelength equivalent medium from a fine-scale one. As the 3-D homogenization problem can be solved via the finite-element method on a tetrahedral mesh, the CSEM is already poised to take advantage of such a method. Incorporating and testing homogenization techniques is work for the immediate future.

\section{CONCLUSIONS}

In this paper we have laid the foundations for the development of a new type of tomographic Earth model, describing 3-D structure on all seismically accessible scales. The construction of this model is based on successive nested refinements within specific subregions and on the assimilation of different types of seismic data through the combination of tomographic techniques.

The CSEM consists of a globe discretized into tetrahedra, with topography, fluid oceans and fluid outer core. The geometric discretization is intended to capture all aspects of potentially resolvable Earth structure, and to be independent of currently popular forward and inverse problem solvers. Furthermore, the CSEM can represent $3-\mathrm{D}$ variations in the full elastic tensor, density and attenuation. This flexible parametrization of the CSEM enables the combination of different inverse problem techniques and data types that may resolve different aspects of Earth structure. As well, it provides a simple, collaborative framework to incorporate subregions generated by a diverse set of research groups, ensuring that a contribution to the global master model need not require massive human and computational resources.

We then designed computationally efficient methods of communicating with the CSEM, and took care to ensure that these methods would not destroy any information previously stored. To complete its initial construction, we interpolated a 1-D radially symmetric model (Dziewoński \& Anderson 1981), a 3-D smooth background model (Ritsema et al. 2004), a 3-D crustal model Meier et al. (2007a,b), as well as higher resolution regional models of Australia, Europe, the South Atlantic and Japan onto the multiscale mesh.

Following this, we described the workflow and summarized several regional refinements which followed this workflow. Each of these sections contain pointers to separate publications describing and interpreting in more detail the relevant submodels. Then, to ensure a global consistency among subregions, and to improve large-scale structure, we described an ongoing global full-waveform inversion based on 225 intermediate-size earthquakes. Finally, we commented on several points, including resolution analysis and future plans for the incorporation of homogenization techniques.

The CSEM is a multiresolution model of the Earth that will reach an increasing degree of completeness as more data on various scales are assimilated. In addition to well-known and robustly reconstructed large-scale structures, the current CSEM also contains smaller scale elements, such as sedimentary basins and smaller slab segments in the Western Mediterranean, that are typically missing in global Earth models. The primary goal of the CSEM framework as presented here is to provide a computational platform for future additions of structural details.
We believe that the CSEM leverages the strengths of inverse methods both modern and classical, and represents a step toward understanding the high-resolution internal structure of our planet.

\section{ACKNOWLEDGEMENTS}

This research was supported by the Swiss National Supercomputing Centre (CSCS) in the form of the GeoScale and $\mathrm{CH} 1$ projects, by the Swiss National Science Foundation (SNF) under grant 200021_149143 and by the Netherlands Organization for Scientific Research (VIDI grant 864.11.008). The authors would like to thank Egill Hauksson, Carl Tape, and an anonymous reviewer, for clear and constructive comments that greatly improved the clarity of this paper. As well, we would like to thank Ebru Bozdag, Yann Capdeville, Nicholas Rawlinson, Martin Schimmel and Brian Kennett for their insights and contributions to various sections of this paper.

\section{REFERENCES}

Aki, K. \& Lee, W.H.K., 1976. Determination of three-dimensional velocity anomalies under a seismic array using first $\mathrm{P}$ arrival times from local earthquakes-1. A homogeneous initial model, J. geophys. Res., 81, 4381-4399.

Aki, K., Christoffersson, A. \& Husebye, E.S., 1976. Determination of threedimensional seismic structure of the lithosphere, J. geophys. Res., 81, 277-296.

Anderson, M.L., Zandt, G., Triep, E., Fouch, M. \& Beck, S., 2004. Anisotropy and mantle flow in the Chile-Argentina subduction zone from shear wave splitting analysis, Geophys. Res. Lett., 31(23), 1-4.

Auer, L., Boschi, L., Becker, T.W., Nissen-Meyer, T. \& Giardini, D., 2014. Savani: a variable resolution whole-mantle model of anisotropic shear velocity variations based on multiple data sets, J. geophys. Res., 119, doi:10.1002/2013JB010773.

Babuška, V. \& Cara, M., 1991. Seismic Anisotropy in the Earth, Kluwer Academic Publishers.

Backus, G.E., 1962. Long-wave elastic anisotropy produced by horizontal layering, J. geophys. Res., 67, 4427-4440.

Backus, G.E. \& Gilbert, F., 1968. The resolving power of gross Earth data, Geophys. J. R. astr. Soc., 16, 169-205.

Backus, G.E. \& Gilbert, F., 1970. Uniqueness in the inversion of inaccurate gross Earth data, Phil. Trans. R. Soc. Lond., A, 266, 123-192.

Becker, T.W. \& Boschi, L., 2002. A comparison of tomographic and geodynamic mantle models, Geochem. Geophys. Geosyst., 3, doi:10.129/2001GC000168.

Bentley, J.L., 1975. Multidimensional binary search trees used for associative searching, Commun. ACM, 18(9), 509-517.

Beyreuther, M., Barsch, R., Krischer, L. \& Wassermann, J., 2010. ObsPy: a Python toolbox for seismology, Seismol. Res. Lett., 81, 47-58.

Bijwaard, H., Spakman, W. \& Engdahl, E.R., 1998. Closing the gap between regional and global traveltime tomography, J. geophys. Res., 103, $30055-$ 30078.

Blacker, T. \& Stephenson, M., 1991. Paving: a new approach to automated quadrilateral mesh generation, Int. J. Numer. Methods Eng., 32, 811-847.

Bohlen, T., 2002. Parallel 3-D viscoelastic finite difference modelling, Comput. Geosci., 28, 887-899.

Boschi, L., 2003. Measures of resolution in global body wave tomography, Geophys. Res. Lett., 30, doi:10.1029/2003GL018222.

Boschi, L., Ekström, G. \& Kustowski, B., 2004. Multiple resolution surface wave tomography: the Mediterranean basin, Geophys. J. Int., 157, 293-304.

Bunge, H.-P., Richards, M.A. \& Baumgardner, J.R., 1997. A sensitivity study of three-dimensional spherical mantle convection at 108 Rayleigh number: effects of depth-dependent viscosity, heating mode, and an endothermic phase change, J. geophys. Res., 102(B6), 11991-12007. 
Capdeville, Y. \& Cance, P., 2015. Residual homogenization for elastic wave propagation in complex media, Geophys. J. Int., 200, 986-999.

Capdeville, Y., Guillot, L. \& Marigo, J.J., 2010a. 1-D non periodic homogenization for the wave equation, Geophys. J. Int., 181, 897-910.

Capdeville, Y., Guillot, L. \& Marigo, J.J., 2010b. 2-D nonperiodic homogenization to upscale elastic media for P-SV waves, Geophys. J. Int., 182, 903-922.

Capdeville, Y., Zhao, M. \& Cupillard, P., 2015. Fast Fourier homogenization for elastic wave propagation in complex media, Wave Motion, 54, $170-186$.

Červený, V., 2005. Seismic Ray Theory, Cambridge Univ. Press.

Chang, S.-J. et al., 2010. Joint inversion for three-dimensional S velocity mantle structure along the Tethyan margin, J. geophys. Res., 115, doi: 10.1029/2009JB007204.

Charléty, J., Voronin, S., Nolet, G., Loris, I., Simons, F., Sigloch, K. \& Daubechis, I.C., 2013. Global seismic tomography with sparsity constraints: comparison with smoothing and damping regularization, J. geophys. Res., 118, 4887-4899.

Chen, P., Zhao, L. \& Jordan, T.H., 2007. Full 3D tomography for the crustal structure of the Los Angeles region, Bull. seism. Soc. Am., 97, 1094-1120.

Colli, L., Fichtner, A. \& Bunge, H.-P., 2013. Full waveform tomography of the upper mantle in the South Atlantic region: imaging westward fluxing shallow asthenosphere?, Tectonophysics, 604, 26-40.

Dahlen, F., Hung, S.-H. \& Nolet, G., 2000. Fréchet kernels for finitefrequency traveltimes - I. Theory, Geophys. J. Int., 141, 157-174.

Dalton, C.A., Ekström, G. \& Dziewonski, A.M., 2008. The global attenuation structure of the upper mantle, J. geophys. Res., 113, doi:10.1029/2007JB005429.

de Kool, M., Rawlinson, N. \& Sambridge, M., 2006. A practical gridbased method for tracking multiple refraction and reflection phases in 3D heterogeneous media, Geophys. J. Int., 167, 353-270.

Deal, M.M. \& Nolet, G., 1996. Nullspace shuttles, Geophys. J. Int., 124, 372-380.

Debayle, E. \& Ricard, Y., 2012. A global shear velocity model of the upper mantle from fundamental and higher Rayleigh mode measurements, $J$. geophys. Res., doi:10.1029/2012JB009288.

Deuss, A. \& Woodhouse, J.H., 2001. Theoretical free-oscillation spectra: the importance of wide band coupling, Geophys. J. Int., 146, 833-842.

Díaz, J. et al., 2009. The IBERARRAY broadband seismic network: a new tool to investigate the deep structure beneath Iberia, ORFEUS Newsl., 8, $1-6$.

Diaz-Steptoe, H., 2013. Full Seismic Waveform Tomography of the Japan Region using Adjoint Methods, PhD thesis, Universiteit Utrecht.

Durek, J.J. \& Ekström, G., 1996. A radial model of anelasticity consistent with long-period surface wave attenuation, Bull. seism. Soc. Am., 86, 144-158.

Dziewoński, A.M. \& Anderson, D.L., 1981. Preliminary reference Earth model, Phys. Earth planet. Inter., 25, 297-356.

Dziewoński, A.M., Hager, B.H. \& O'Connell, R.J., 1977. Large-scale heterogeneities in the lower mantle, J. geophys. Res., 82, 239-255.

Ekström, G., 2011. A global model of Love and Rayleigh surface wave dispersion and anisotropy, 25-250 s, Geophys. J. Int., 187, $1668-1686$.

Faccenna, C. et al., 2014. Mantle dynamics in the Mediterranean, Rev. Geophys., 52(3), 283-332.

Faccioli, E., Maggio, F., Quarteroni, A. \& Tagliani, A., 1996. Spectraldomain decomposition methods for the solution of acoustic and elastic wave equations, Geophysics, 61:4, 1160-1174.

Ferreira, A.M.G., Woodhouse, J.H., Visser, K. \& Trampert, J., 2010. On the robustness of global radially anisotropic surface wave tomography, $J$. geophys. Res., 115, doi:1029/2009JB006716.

Fichtner, A., 2014. Source and processing effects on noise correlations, Geophys. J. Int., 197, 1527-1531.

Fichtner, A. \& Trampert, J., 2011. Resolution analysis in full waveform inversion, Geophys. J. Int., 187, 1604-1624.

Fichtner, A. \& van Leeuwen, T., 2015. Resolution analysis by random probing, J. geophys. Res., 120, doi:10.1002/2015JB012106.
Fichtner, A. \& Villaseñor, A., 2015. Crust and upper mantle of the western Mediterranean - Constraints from full-waveform inversion, Earth planet. Sci. Lett., 428, 52-62.

Fichtner, A., Bunge, H.-P. \& Igel, H., 2006. The adjoint method in seismology-I. Theory, Phys. Earth planet. Inter., 157, 86-104.

Fichtner, A., Kennett, B.L.N., Igel, H. \& Bunge, H.-P., 2008. Theoretical background for continental- and global-scale full-waveform inversion in the time-frequency domain., Geophys. J. Int., 175, 665-685.

Fichtner, A., Kennett, B.L.N., Igel, H. \& Bunge, H.-P., 2009a. Full seismic waveform tomography for upper-mantle structure in the Australasian region using adjoint methods, Geophys. J. Int., 179, 1703-1725.

Fichtner, A., Kennett, B.L.N., Igel, H. \& Bunge, H.-P., 2009b. Spectralelement simulation and inversion of seismic waves in a spherical section of the Earth, J. Numer. Anal. Ind. Appl. Math., 4, 11-22.

Fichtner, A., Kennett, B.L.N., Igel, H. \& Bunge, H.-P., 2010. Full waveform tomography for radially anisotropic structure: new insight into present and past states of the Australasian upper mantle, Earth planet. Sci. Lett., 290, 270-280.

Fichtner, A., Fishwick, S., Yoshizawa, K. \& Kennett, B.L.N., 2012. Optimal spherical spline filters for the analysis and comparison of regional-scale tomographic models, Phys. Earth planet. Inter., 190-191, 44-50.

Fichtner, A., Kennett, B.L.N. \& Trampert, J., 2013a. Separating intrinsic and apparent anisotropy, Phys. Earth planet. Inter, 219, 11-20.

Fichtner, A., Saygin, E., Taymaz, T., Cupillard, P., Capdeville, Y. \& Trampert, J., 2013b. The deep structure of the North Anatolian Fault Zone, Earth planet. Sci. Lett., 373, 109-117.

Fichtner, A., Trampert, J., Cupillard, P., Saygin, E., Taymaz, T., Capdeville, Y. \& Villasenor, A., 2013c. Multi-scale full waveform inversion, Geophys. J. Int., 194, 534-556.

Friederich, W., 2003. The S-velocity structure of the East Asian mantle from inversion of shear and surface waveforms, Geophys. J. Int., 153, 88-102.

Giardini, D., Li, X.-D. \& Woodhouse, J.H., 1987. Three-dimensional structure of the Earth from splitting in free-oscillation spectra, Nature, 325, 405-411.

Gokhberg, A. \& Fichtner, A., 2015. Full-waveform inversion on heterogeneous HPC systems, Comp. Geosci., in press.

Hanasoge, S.M., 2013a. The influence of noise sources on cross-correlation amplitudes, Geophys. J. Int., 192, 295-309.

Hanasoge, S.M., 2013b. Measurements and kernels for source-structure inversions in noise tomography, Geophys. J. Int., 192, 971-985.

Hoernle, K. et al., 2008. Arc-parallel flow in the mantle wedge beneath Costa Rica and Nicaragua., Nature, 451(7182), 1094-1097.

Igel, H., Djikpesse, H. \& Tarantola, A., 1996. Waveform inversion of marine reflection seismograms for P impedance and Poisson's ratio., Geophys. J. Int., 124, 363-371.

International Seismological Centre, 2012. On-line Bulletin, Int. Seis. Cent., Thatcham, United Kingdom, http://www.isc.ac.uk.

Ishii, M. \& Tromp, J., 2001. Even-degree lateral variations in the Earth's mantle constrained by free oscillations and the free-air gravity anomaly., Geophys. J. Int., 145, 77-96.

Ishii, M. \& Tromp, J., 2004. Constraining large-scale mantle heterogeneity using mantle and inner-core sensitive normal modes., Phys. Earth planet. Inter., 146, 113-124.

Kamei, R., Pratt, R.G. \& Tsuji, T., 2012. Waveform tomography imaging of a megasplay fault system in the seismogenic Nankai subduction zone, Earth planet. Sci. Lett., 317-318, 343-353.

Kennett, B., Widiyantoro, S. \& van der Hilst, R., 1998. Joint seismic tomography for bulk-sound and shear wave speed in the Earth's mantle, $J$. geophys. Res., 103, 12 469-12 493.

Kennett, B.L.N. \& Engdahl, E.R., 1991. Traveltimes for global earthquake location and phase identification, Geophys. J. Int., 105, 429-465.

Kennett, B.L.N., Engdahl, E.R. \& Buland, R., 1995. Constraints on seismic velocities in the Earth from traveltimes., Geophys. J. Int., 122, 108-124.

Komatitsch, D., 2011. Fluid-solid coupling on a cluster of GPU graphics cards for seismic wave propagation, C. R. Mec., 339, 125-135.

Komatitsch, D. \& Tromp, J., 2002a. Spectral-element simulations of global seismic wave propagation, part II: 3-D models, oceans, rotation, and gravity, Geophys. J. Int., 150, 303-318. 
Komatitsch, D. \& Tromp, J., 2002b. Spectral-element simulations of global seismic wave propagation, part I: Validation, Geophys. J. Int., 149, 390-412.

Komatitsch, D. \& Vilotte, J.P., 1998. The spectral element method: an effective tool to simulate the seismic response of 2D and 3D geological structures, Bull. seism. Soc. Am., 88, 368-392.

Komatitsch, D., Erlebacher, G., Göddeke, D. \& Michea, D., 2010. Highorder finite-element seismic wave propagation modeling with MPI on a large GPU cluster, J. Comput. Phys., 229, 7692-7714.

Komatitsch, D., Xie, Z., Bozdag, E., Peter, D., de Andrade, E.S., Liu, Q. \& Tromp, J., 2015. Exact time-reversal viscoelastic sensitivity kernels with parsimonious storage for full waveform inversion, Geophys. J. Int., in press.

Krischer, L., Fichtner, A., Žukauskaitè, S. \& Igel, H., 2015. Large-scale seismic inversion framework, Seismol. Res. Lett., 86, 1198-1207.

Lebedev, S. \& van der Hilst, R.D., 2008. Global upper-mantle tomography with the automated multimode inversion of surface and S-wave forms, Geophys. J. Int., 173, 505-518.

Lekić, V. \& Romanowicz, B., 2011. Inferring upper-mantle structure by full waveform tomography with the spectral-element method, Geophys. J. Int., 185, 799-831.

Levshin, A. \& Ratnikova, L., 1984. Apparent anisotropy in inhomogeneous media, Geophys. J. R. astr. Soc., 76, 65-69.

Li, C., van der Hilst, R.D., Engdahl, E.R. \& Burdick, S., 2008. A new global model for P-wavespeed variations in the Earth's mantle, Geochem. Geophys. Geosyst., 9, doi:10.1029/2007GC001806.

Lobkis, O.I. \& Weaver, R.L., 2001. On the emergence of the Green's function in the correlations of a diffuse field, J. acoust. Soc. Am., 110, 3011-3017.

Malcolm, A.E., Scales, J. \& van Tiggelen, B.A., 2004. Extracting the Green function from diffuse, equipartitioned waves, Phys. Rev. E, 70, doi:10.1103/PhysRevE.70.015601.

Megies, T., Beyreuther, M., Barsch, R., Krischer, L. \& Wassermann, J., 2011. Obspy - what can it do for data centers and observatories?, Ann. Geophys., 54, 47-58.

Mégnin, C. \& Romanowicz, B., 2000. The 3D shear velocity structure of the mantle from the inversion of body, surface and higher modes wave forms, Geophys. J. Int., 143, 709-728.

Meier, U., Curtis, A. \& Trampert, J., 2007a. Global crustal thickness from neural network inversion of surface wave data, Geophys. J. Int., 169, 706-722

Meier, U., Curtis, A. \& Trampert, J., 2007b. Fully nonlinear inversion of fundamental mode surface waves for a global crustal model., Geophys. Res. Lett., 34, doi:10.1029/2007GL030989.

Moczo, P., Kristek, J., Vavrycuk, V., Archuleta, R. \& Halada, L., 2002. 3D heterogeneous staggered-grid finite-difference modeling of seismic motion with volume harmonic and arithmetic averaging of elastic moduli, Bull. seism. Soc. Am., 92, 3042-3066.

Moczo, P., Kristek, J. \& Galis, M., 2014. The Finite-Difference Modelling of Earthquake Motions: Waves and Ruptures, Cambridge University Press.

Nettles, M. \& Dziewoński, A.M., 2008. Radially anisotropic shear velocity structure of the upper mantle globally and beneath North America, $J$. geophys. Res., 113, doi:10.1029/2006JB004819.

Nolet, G., 1978. Simultaneous inversion of seismic data, Geophys. J. R. astr. Soc., 55, 679-691.

Nolet, G., Montelli, R. \& Virieux, J., 1999. Explicit, approximate expressions for the resolution and a posteriori covariance of massive tomographic systems, Geophys. J. Int., 138, 36-44.

Panning, M.P., Capdeville, Y. \& Romanowicz, B., 2009. Seismic waveform modelling in a 3-D Earth using the Born approximation: potential shortcomings and a remedy, Geophys. J. Int., 177, 161-178.

Parisi, L., Ferreira, A. M.G. \& Capdeville, Y., 2015. Validity domain of the Born approximation for seismic waveform modelling in realistic 3-D Earth structure, Geophys. J. Int., 200, 908-914.

Pratt, R.G., 1999. Seismic waveform inversion in the frequency domain, part 1: Theory and verification in a physical scale models, Geophysics, 64, 888-901.
Rawlinson, N. \& Sambridge, M., 2004. Wavefront evolution in strongly heterogeneous layered media using the fast marching method, Geophys. J. Int., 156, 631-647.

Resovsky, J. \& Ritzwoller, M., 1999. A degree 8 mantle shear velocity model from normal mode observations below $3 \mathrm{mHz}$, J. geophys. Res., 104, 993-1014.

Ritsema, J. \& van Heijst, H.J., 2002. Constraints on the correlation of P- and S-wave velocity heterogeneity in the mantle from P, PP, PPP and PKPab traveltimes, Geophys. J. Int., 149, 482-489.

Ritsema, J., vanHeijst, H. \& Woodhouse, J.H., 1999. Complex shear wave velocity structure imaged beneath Africa and Iceland, Science, 286, 1925-1928.

Ritsema, J., vanHeijst, H. \& Woodhouse, J.H., 2004. Global transition zone tomography, J. geophys. Res., 109, doi:10.1029/2003JB002610.

Ritsema, J., Deuss, A., van Heijst, H.J. \& Woodhouse, J.H., 2011. S40RTS: a degree-40 shear-velocity model for the mantle from new Rayleigh wave dispersion, teleseismic traveltime and normal-mode splitting function measurements, Geophys. J. Int., 184, 1223-1236.

Schaeffer, A.J. \& Lebedev, S., 2013. Global shear speed structure of the upper mantle and transition zone, Geophys. J. Int., 194, $417-449$.

Schäfer, J., Boschi, L. \& Kissling, E., 2011. Adaptively parametrized surface wave tomography: methodology and a new model of the European upper mantle, Geophys. J. Int., 186, 1431-1453.

Schoenberg, M. \& Muir, F., 1989. A calculus for finely layered anisotropic media, Geophysics, 54, 581-589.

Seriani, G. \& Priolo, E., 1994. Spectral element method for acoustic wave simulation in heterogeneous media, Finite Elem. Anal. Des., 16, $337-348$.

Shapiro, N.M., Campillo, M., Stehly, L. \& Ritzwoller, M., 2005. High resolution surface wave tomography from ambient seismic noise, Science, 307, 1615-1618.

Sjaardema, G.D., Schoof, L.A. \& Yarberry, V.R., 2006. EXODUS II : a Finite Element Data Model, Tech. Rep. November 1995, Sandia National Laboratories.

Smithyman, B.R. \& Clowes, R.M., 2012. Waveform tomography of field vibroseis data using an approximate $2 \mathrm{~d}$ geometry leads to improved velocity models, Geophysics, 77(1), R33-R43.

Spakman, W., van der Lee, S. \& van der Hilst, R., 1993. Travel-time tomography of the European-Mediterranean mantle down to $1400 \mathrm{~km}$, Phys. Earth planet. Inter., 79, 3-74.

Tape, C., Liu, Q., Maggi, A. \& Tromp, J., 2010. Seismic tomography of the southern California crust based upon spectral-element and adjoint methods., Geophys. J. Int., 180, 433-462.

Tarantola, A., 1984. Inversion of seismic reflection data in the acoustic approximation, Geophysics, 49, 1259-1266.

Tarantola, A., 1988. Theoretical background for the inversion of seismic waveforms, including elasticity and attenuation, Pure appl. Geophys., 128, 365-399.

Tatsumi, Y., 1989. Migration of fluid phases and genesis of basalt magmas in subduction zones, J. geophys. Res., 94(B4), 4697-4707.

Trampert, J. \& Woodhouse, J.H., 1995. Global phase velocity maps of Love and Rayleigh waves between 40 and 150 seconds, Geophys. J. Int., 122, 675-690.

Trampert, J. \& Woodhouse, J.H., 2003. Global anisotropic phase velocity maps for fundamental mode surface waves between 40 and $150 \mathrm{~s}$, Geophys. J. Int., 154, 154-165.

Tromp, J., Tape, C. \& Liu, Q., 2005. Seismic tomography, adjoint methods, time reversal and banana-doughnut kernels, Geophys. J. Int., 160, 195-216.

Tromp, J., Luo, Y., Hanasoge, S. \& Peter, D., 2010. Noise cross-correlation sensitivity kernels, Geophys. J. Int., 183, 791-819.

Tsai, V.C., 2010. The relationship between noise correlation and the Green's function in the presence of degeneracy and the absence of equipartition, Geophys. J. Int., 182, 1509-1514.

Wang, Z. \& Dahlen, F.A., 1995. Spherical-spline parameterization of three-dimensional Earth models, Geophys. Res. Lett., 22, 30993102. 
Wang, Z., Tromp, J. \& Ekström, G., 1998. Global and regional surface-wave inversion: a spherical-spline parameterization, Geophys. Res. Lett., 25(2), 207-210.

Wapenaar, K., 2004. Retrieving the elastodynamic Green's function of an arbitrary inhomogeneous medium by cross correlation, Phys. Rev. Lett., 93, doi:10.1103/PhysRevLett.93.254301.

Wapenaar, K. \& Fokkema, J., 2006. Green's function representations for seismic interferometry, Geophysics, 71, S133-S146.

Weaver, R.L. \& Lobkis, O.I., 2004. Diffuse fields in open systems and the emergence of Green's function, J. acoust. Soc. Am., 116, 2731-2734.

Woodhouse, J.H. \& Dziewoński, A.M., 1984. Mapping the upper mantle: three-dimensional modeling of Earth structure by inversion of seismic waveforms, J. geophys. Res., 89, 5953-5986.

Yanovskaya, T.B., 1997. Resolution estimation in the problems of seismic ray tomography, Izv. Phys. Solid Earth, 33, 76-80.

Yomogida, K., 1992. Fresnel zone inversion for lateral heterogeneities in the Earth, Pure appl. Geophys., 138, 391-406.

Yoshizawa, K. \& Ekström, G., 2010. Automated multimode phase speed measurements for high-resolution regional-scale tomography: application to North America, Geophys. J. Int., 183, 1538-1558.

Yoshizawa, K. \& Kennett, B.L.N., 2005. Sensitivity kernels for finitefrequency surface waves, Geophys. J. Int., 162, 910-926.

Zhao, D., 2004. Global tomographic images of mantle plumes and subducting slabs: insight into deep Earth dynamics, Phys. Earth planet. Inter., 146(1-2), 3-34.

Zhu, H., Bozdağ, E. \& Tromp, J., 2015. Seismic structure of the European upper mantle based on adjoint tomography, Geophys. J. Int., 201, 18-52.

\section{APPENDIX A: MODEL STORAGE}

We decided to store the model as a series of exodusII files (Sjaardema et al. 2006), a popular format in finite-element applications, for the following reasons. First, the exodusII format is built on top of NetCDF-4 and HDF5, which allows for parallel, binary and portable file access. Secondly, the ease with which exodusII files can be incorporated into finite-element codes bodes well for future interfaces to various forward problem solvers. Thirdly, many popular visualization toolkits provide native support for exodusII files, easing model inspection and interpretation. It is worth mentioning as well that the use of exodusII files means that the tie to Trelis is not absolute. As the file format is open source, any suitable meshing package is appropriate.

\section{APPENDIX B: SOLVER INTERFACES}

Currently, interfaces are written between the CSEM and two widely used wave propagation codes: SPECFEM3D_GLOBE (Komatitsch \& Tromp 2002a,b) and SES3D (Fichtner et al. 2009b; Gokhberg \& Fichtner 2015). Additional interfaces exist with the traveltime tomography code FMTOMO (Rawlinson \& Sambridge 2004; de Kool et al. 2006), which uses a fast marching method and the mantle convection code TERRA (Bunge et al. 1997). While the specific implementation of the interfaces differs, each operates by first generating a 'request file', which contains pointwise locations within the Earth at which parameters are needed. Additional information, such as discretization information and the desired elastic symmetry system, is required. Following this, the parameters are extracted from the CSEM following the procedure outlined in Section 2.3.2.

Splitting the mesh as described in Section 4.1 ensures that no single mesh file becomes unreasonably large. The use of the HDF5 compression algorithms in the NetCDF-4 API keeps the size of the request files down as well. For example, a typical Specfem global wave propagation test run on 150 cores generated request files containing a total of approximately $3 \times 10^{9} \mathrm{GLL}$ points. The compressed size of these files was on the order of 2 GB. The parallel I/O afforded by specifying one request and parameter file per processor allowed the meshing to be completed very quickly, with the csemRequest and csemAccept stages together taking less than one minute. 